\title{
CONFLICTO, POLÍTICA Y POLEMOLOGÍA EN EL PENSAMIENTO DE JULIEN FREUND
}

\section{Jerónimo Molina *}

\author{
"El lenguaje sociológico se ha convertido \\ en la lengua oficial de la democracia moderna" \\ (P. Manent ${ }^{1}$ )
}

Julien Freund, lorenés de nación (Henridorff, 1921), estará para siempre sentimentalmente asociado a la región alsaciana, a la ciudad de Estrasburgo y, particularmente, a Villé, apacible pueblo en el corazón de los Vosgos del que hizo, como le gustaba decir, su San Casciano. Allí murió en el mes de septiembre de 1993. La luctuosa circunstancia, que en ocasiones puede determinar una repentina $\mathrm{y}$, por tanto, circunstancial atención de la comunidad científica, apenas si ha servido para que se interesen por el pensamiento del gran polígrafo francés unos cuantos especialistas de dispar profesión intelectual. Los motivos del desconocimiento casi general de la obra de este escritor no nos pueden ocupar ahora, si bien debe manifestarse la sorpresa que este extremo causa en cualquier lector instruido que se aproxime a su pensamiento, un saber vasto que recorre ejemplarmente los saberes político, polemológico, económico y jurídico, entre otros ${ }^{2}$. En términos generales, donde más atención se le ha dedicado, a juzgar por las traducciones de sus obras y los estudios y artículos sobre su pensamiento, ha sido en Italia y en el mundo hispánico, en Argentina y particularmente en España ${ }^{3}$. Así, debe mencionarse la reciente publicación de la que probablemente es la primera monografía europea sobre la filosofía política del escritor francés ${ }^{4}$. Con este trabajo aspiramos a la exposición ordenada de su aportación científica a la sociología y, en particular, a la polemología. Se parte para ello de la personal recepción que el autor hizo de la

* Departamento de Sociología y Política Social de la Universidad de Murcia 
tradición sociológica, de su crítica al sociologismo, tan alejado de la verdadera sociología, y, finalmente, de su óptica epistemológica y fenomenológica tan necesaria, y en ocasiones tan preterida, en el desarrollo de los saberes sociológicos ${ }^{5}$.

\section{SEMBLANZA INTELECTUAL Y UNIVERSITARIA}

"Freund significa amigo en alemán". Quien se presentaba de este modo ante sus alumnos de la Facultad de Ciencias sociales de la Universidad de Ciencias Humanas de Estrasburgo, todos los principios de curso, no era un profesor contracultural ni un demagogo. Se trataba del profesor de sociología Julien Freund, el cual, después de haber recorrido casi todos los escalones administrativos del sistema educativo francés, recaló en 1965 en la Universidad estrasburguesa. Dejando a un lado la situación académica y administrativa de la Sorbona, no puede decirse, según es sabido, que en ese año se estuviese cerca de la consolidación los estudios universitarios de sociología. En la universidad alsaciana se contaba empero con los ilustres precedentes del magisterio de Georg Simmel, a quien las envidias le obligaron a buscar la cátedra lejos de Berlín en 1914, o el del ruso-francés Georges Gurvitch.

Freund, estudioso y traductor de la obra de los fundadores de la tradición sociológica, impulsor de las disciplinas sociológicas en la Francia del Este y maestro de tantos sociólogos, no se reconocía a sí mismo la condición de verdadero sociólogo. Al autor le gustaba puntualizar, sin embargo, que él se había limitado a desempeñar las funciones propias de una cátedra de sociología. Como profesor y responsable del departamento correspondiente, Freund fue serio y riguroso, sin dejar lugar a la improvisación. Sobre todo en lo que afectaba al futuro de las disciplinas sociológicas en el seno de su Universidad. No hay rigor sin disciplina, solía decir. Nunca, a lo largo de su carrera de universitario, se presentó delante de los alumnos sin tener previamente redactado el texto del curso. "Lejos de obstaculizar la espontaneidad, este método la favorece, pues el estudiante constata en seguida que se inscribe en la continuidad de un pensamiento reflexivo y que no se trata de un 'relleno' o de palabrería" .

En octubre de 1960, contando con el patrocinio de su amigo y mentor Raymond Aron, a la sazón su director de tesis, ingresó en el Centre National de la Recherche Scientifique (C. N. R. S.) Curiosamente, Freund había presentado su candidatura a los concursos de la sección de filosofía, pues esa era su formación y la aspiración lógica de quien era Agregé de filosofía en la enseñanza secundaria francesa. Sin embargo, su curriculum vitae fue transferido a la sección de sociología. "Vi todas mis posibilidades reducidas a la nada, ha escrito Freund. Aron, igualmente sorprendido, empleó toda su autoridad para que me admitiese la comisión de sociología, de la que afortunadamente era miembro" ". El caso de Freund, el del filósofo devenido sociólogo, resultó ser algo corriente en Francia, empezando por la generación de normaliens a la que perteneció Aron.

Su llegada a la facultad, según se ha señalado, se produjo en vísperas del 
desbordamiento científico de las disciplinas sociológicas tradicionales. La especialización y la fragmentación de su dominio intelectual, en función de la formalización de problemas nuevos o del replanteamiento de los viejos, avanzaba a pasos agigantados, especialmente en las universidades de los Estados Unidos de América. Mas la consolidación del estatuto científico de la disciplina no explica por sí sola su éxito. Hay que contar también con los efectos de la moda de lo social, determinante, en los ambientes juveniles, de la rápida saturación de ciertas especialidades.

El curriculum administrativo de Freund le señala como un creador de instituciones, entre las que destaca el Instituto de Polemología (Institut de Polémologie), el primero en su género ${ }^{8}$. Fiel a su concepción del origen histórico de los estudios sociológicos, consideraba que la Sociología no se instituyó arbitraria o discrecionalmente, sino como respuesta a las exigencias del mundo moderno. Su proyecto administrativo e intelectual del Institut constituye, pues, "la expresión en el orden de la investigación científica de la profunda mutación que afecta a las sociedades modernas" . "Para no defraudar a quienes me elevaron a la profesión universitaria, escribió en otro lugar, hice todo lo que estuvo en mi mano para desarrollar la ciencia sociológica propiamente dicha en Estrasburgo" ${ }^{10}$. Esto incluía también la creación en 1967 del Centre de Recherches et d'Études en Sciencies Sociales y, poco después, en 1973, del Laboratoire de Sociologie Régionale ${ }^{11}$.

Como director del departamento (Unité d'enseignement et de recherche o U.E.R.) de sociología en el momento de expansión de estas disciplinas, viose forzado a dimitir de su responsabilidades en 1973. Para él era inaceptable el mal uso universitario consistente en rebajar arbitrariamente la dotación económica destinada a su disciplina, en plena efervescencia, y cuyo periodo de gracia presupuestaria se acababa de abrir, para beneficiar a los departamentos ya consolidados. La opinión que se impuso fue la de las U.E.R. tradicionales, cuya mayoría facilitó la formalización de esa decisión. De aquí arranca el affaire Freund, pues este último se resistió a la manipulación. Después de un cruce de notas de prensa entre Freund y otros miembros del claustro universitario, se quiso liquidar el asunto con una reunión claustral extraordinaria para reconvenir al díscolo profesor. Después de la amonestación pública consumóse una nueva decepción de Freund, añadida a la desesperación juvenil del socialista y resistente que había sido, ante lo que llamaría después la "terreur blanche", o terror ideológico que sucedió a la Liberación de Francia ${ }^{12}$.

Su reacción, vehemente al principio, consistió en las renuncias sucesivas a todo cargo o función administrativa universitaria. Finalmente, en 1979, se acogió a la jubilación anticipada, a la que tenía derecho en virtud de su participación en la Resistencia. La independencia de espíritu de Freund estuvo por encima del ninguneo administrativo, de las traiciones personales o del mismo cuestionamiento de su presencia en el tribunal de algunas tesis doctorales. Con 58 años, dijo el autor en su magnifico esbozo autobiográfico, "tenía más cosas que hacer que oponerme permanentemente a las chifladuras de los supuestos progresistas y demócratas"13. 
A continuación se exponen algunas de las conexiones esenciales de la sociología freundeana con el caudal de la sociología clásica, pues Freund dio nueva vida a temas relativamente olvidados o monopolizados por doctrinas sociologistas o incluso por ideologías políticas. En los diversos artículos y monografías que el autor dedicó a los padres de la sociología resulta gratificante descubrir que lo moderno hunde sus raíces en la tradición. Así, las concepciones freundeanas del conflicto o del poder beben, respectivamente, en Simmel y en Pareto. Del mismo modo, las bases de la epistemología de Freund, se encuentran, sin duda ninguna, en la relectura permanente de la obra de Weber. ¿Cuáles son las aportaciones más notables de Freund al saber sociológico de las últimas décadas? Si hubiese que sintetizarlas en dos grandes apartados, deberían figurar su teoría epistemológica fenomenológica de las esencias y su elaboración sistemática de una sociología del conflicto (polémologie). Mas antes de abordar esta temática conviene establecer las afinidades sociológicas del autor.

\section{LAS AFINIDADES SOCIOLÓGICAS}

Weber, Simmel, Pareto y Durkheim forman parte de la magnífica generación europea de fin de siglo ${ }^{14}$ que se encargó de dar rango científico a la Sociología. En sus obras respectivas se acusan, en diversa medida y desde puntos de vista a veces insólitos, no sólo las novedades metodológicas y epistemológicas, inspiradas por el desarrollo de las ciencias físico-naturales y por el neokantismo, sino también la fractura esencial que separa el siglo XX del tiempo precedente. Aron, en su libro sobre Las etapas del pensamiento sociológico, dictaminó que la preocupación por la transformación de las relaciones entre ciencia y religión fue, aunque no siempre de manera consciente, uno de los supuestos intelectuales de los fundadores de la sociología moderna. El tema, en efecto, aparece como en filigrana en sus obras. Pero la cuestión última tenía un trasfondo escatológico: ¿puede la racionalidad científica colmar de sentido la vida humana, individual y colectiva, igual que las creencias religiosas? ${ }^{15}$

\section{MAX WEBER O LA SOCIOLOGÍA DE LOS ANTAGONISMOS}

Max Weber perteneció a las grandes promociones de profesores alemanes que marcaron la orientación intelectual del cambio de siglo. La ciencia alemana, que acometía empresas en todos los campos, era envidiada en su momento por otras ciencias nacionales, al parecer raquíticas, pues lo alemán equivalía entonces a moderno. Desde España, por ejemplo, lo alemán se veía cual fermento que instituciones como la Junta de Ampliación de Estudios pretendían poner al alcance de las inteligencias juveniles.

Weber, pilar de la sociología moderna, fue una personalidad superior en el panorama alemán. Freund descubrió su obra después de la guerra, si bien ya había 
entrado en contacto con ella en 1941, en Clermont-Ferrand, a través de la lectura del libro La sociologie allemande contemporaine, de Aron. Profundamente decepcionado por las antinomias de la vida política, le arrebató la lectura de la famosa conferencia Politik als Beruf. La suerte de heroísmo trágico que rezuman los supuestos filosóficos de Weber le impactó. "Lo que tenemos ante nosotros, decía el autor de Economía y sociedad en 1919, no es la alborada del estío, sino una noche polar de una dureza y una oscuridad heladas"16. En otra de las páginas preferidas y más citadas por Freund, el gran sociólogo alemán se hacía espectador de un paisaje digno del infierno del Dante: "los numerosos dioses antiguos, desmitificados y convertidos en poderes impersonales, salen de sus tumbas, quieren dominar nuestras vidas y recomienzan entre ellos la eterna lucha”. En esa reversión insospechada e irónica del viejo monoteísmo cristiano y racionalista se encuentra, tal vez, el destino de la Civilización occidental, convertida, en la postmodernidad, en el reino de la reivindicación permanente ${ }^{17}$.

La política, como sabía muy bien Weber, no es una actividad de segundo rango, expuesta sin más consecuencias a la defección y a la arbitrariedad personales. De ser así, tal vez cabría buscarle un sustitutivo o, cuando menos, confiar en la regeneración de la vida pública apartando de ella a los profesionales viciosos. Pero la raíz del mal no está en la falta de probidad personal. "Quien hace política, dice Weber, pacta con los poderes diabólicos que acechan en torno de todo poder"18. Esos poderes arcanos nunca se apiadarán del político bisoño que sacrifica en el altar de la ética de convicción y que no tiene en cuenta que del bien no se sigue, forzosamente, el bien y que, al menos en política, el mal no siempre engendra mal. En este sentido, los resultados de las acciones humanas rara vez se identifican plenamente con las intenciones de partida. Incluso si media la buena fe, ningún proyecto o empresa puede escapar a la irracionalidad ética del mundo. Para Weber, toda teodicea es, precisamente, un intento de superar una constatación terrible y primordial: "cómo es posible que un poder que se supone, a la vez, infinito y bondadoso haya podido crear este mundo irracional del sufrimiento inmerecido, la injusticia impune y la estupidez irremediable". Weber enfrentaba así a sus lectores a lo que él denominó la paradoja de las consecuencias, noción que, según Freund, es "uno de los más importantes descubrimientos hechos en el dominio de las Ciencias sociales en este siglo" "19. A la dimensión paradójica de la experiencia ética de la humanidad, Weber añadió, en una relación de casi mutuo aliento, el antagonismo de los valores. Esta opinión ha sido desarrollada por Freund en distintos lugares ${ }^{20}$.

Y precisamente en la obra freundeana tuvieron una especial incidencia las consecuencias extraídas de la noción del antagonismo de los valores. La lucha sin final $3 / 4 y$ acaso sin objeto de los valores o, para expresarlo con más rigor, de los fines humanos, incluso de las pasiones, corroborada por los presocráticos y Aristóteles, es determinante de su explicación metafísica del movimiento histórico. El presupuesto del agon o de los contrarios preside su crítica del moralismo político, 
demasiado dado a forjar mentalmente sociedades armónicas. También su crítica de escuelas sociológicas como la de la Investigación para la paz, de Johan Galtung, que Freund consideraba demasiado ideologizadas y, en última instancia, polemógenas.

Weber no dejó, en rigor, una escuela. En cambio, sí ha tenido lectores e intérpretes de variadísima competencia e intención. "Todo pensamiento, escribe Freund, incluso el más coherente, contiene los elementos de su propia negación. No nos sorprendamos si hasta las ideas de los autores más geniales dan lugar a una abundancia de interpretaciones, bien meramente divergentes, bien francamente contradictorias. Para un escritor, sea poeta o físico, biólogo o sociólogo, no ser nunca el objeto de un debate es signo de mediocridad" ${ }^{21}$. Por lo demás, su recepción ha sido irregular: temprana, al menos comparativamente, en países como Francia y España; tardía, como se sabe, en el mundo anglosajón.

Un escritor político del mundo hispánico, Francisco Javier Conde ${ }^{22}$, fue el primero en servirse, mucho antes que la Political Science norteamericana, de los tipos ideales de legitimidad elaborados por Weber. Concretamente en 1941, "para caracterizar y definir un sistema político" ${ }^{\prime 2}$. Aron ha escrito, a propósito de la fecha de publicación de su libro La sociologie allemande contemporaine, que "en 1935, la mayoría de los sociólogos alemanes de los que yo me ocupaba eran desconocidos o mal conocidos. L'Année sociologique había dado cuenta de algunos trabajos de Max Weber, en particular del ensayo sobre el puritanismo y el espíritu del capitalismo"24.

Freund ha sido uno de los difusores de la sociología y del pensamiento de Weber en Francia. Sus escritos y traducciones fueron para ello decisivos. En 1959 vertió al francés, con un prólogo de Aron, las conferencias sobre la ciencia y la política como vocación: Le savant et le politique (Plon). En 1965 hizo lo mismo con algunos escritos epistemológicos del sabio alemán, publicados con el título Essais sur la théorie de la science (Plon) y prologados con una importante introducción de Freund a su pensamiento ${ }^{25}$. Este importantísimo trabajo, que estableció la versión francesa de conceptos como la Wertfrei ("neutralité axiologique"), fue presentado además como tesis secundaria, patrocinada por Paul Ricoeur. Posteriormente, se ramificó la investigación freundeana sobre la obra de Weber a fin de cubrir casi todos sus campos. Aparecieron, así, Sociologie de Max Weber ${ }^{26}$ y el sugestivo libro Max Weber, ya mencionado, ensayístico y antológico al cincuenta por ciento, en donde el escritor puso en claro los presupuestos filosóficos de la sociología de Weber. Es conocido el desprecio sui generis de este último por la metafísica, "actitud extraña en Weber, no obstante, pues fue uno de los espíritus más abiertos, independientes y originales de su tiempo"27. En opinión de Freund, las invectivas del alemán contra la metafísica no son una verdadera impugnación de este tipo de reflexión; expresarían en realidad su hostilidad a ciertas filosofías de la historia ${ }^{28}$.

\section{EL PENSAMIENTO IMPERTINENTE DE VILFREDO PARETO}

A Pareto, sucesor de L. Walras en su cátedra de economía de Lausana, le 
preocupó, como a Durkheim, la evaporación de las creencias en las que está basado el consenso social; aquello que, por decirlo de otra manera, garantiza la normalidad. Vivió en sus propias carnes los efectos de lo que se denominó, con término no siempre feliz, anomia. Pareto, obsesionado por sacar a la luz los residuos que se ocultan tras las justificaciones que fabrica la soberbia intelectual (las derivaciones), se dio cuenta de que la forma política estatal, desprovista de justificaciones trascendentes, está abocada a refundar los nuevos principios de su auctoritas, so riesgo de aparecer, como le sucede al rey de la fábula, desnudo de majestad, poder puro, a lo peor fuerza. Freund leyó con atención a Pareto, impulsado al principio, tal vez, por la simpatía que en él despertaron las inteligencias non gratas. "No podemos soportar, escribió en 1974, a quien nos arrebata las ilusiones y, además, nos muestra que las palabras que utilizamos implican ciertas ficciones" ${ }^{29}$. Habituado a encontrar la lucidez de un pensamiento a contracorriente y libre en los escritores descalificados por el intelectualismo, Freund hizo caso omiso de la mala prensa del sociólogo italiano.

Con independencia de sus aportaciones en otros campos ${ }^{30}$, aquí tan sólo interesa resaltar las líneas maestras de su sociología del poder. Pues, en opinión que compartimos con el profesor Piet Tommissen, una de las claves de la obra freundeana es la recepción de la teoría del poder de Pareto $^{31}$. La misma importancia hay que dar a la concepción paretiana de la fuerza y la inserción de esta última en la lógica específica de la política ${ }^{32}$. La política, pero sobre todo el poder, es la gran evidencia de la obra del sabio italiano. Sus intuiciones sobre el particular, aun siendo menos sistemáticas que las contenidas en la sociología de la dominación de Weber, tienen un alcance similar. Sin embargo, mientras que Weber pasa por un Machtpolitiker, Pareto es a veces tachado de inspirador del maquiavelismo moderno. ¿Por qué ha corrido Pareto peor suerte que otros realistas políticos? Tal vez buscó él mismo su destino de escritor maldito y denostado ${ }^{33}$. Pero ni su pensamiento ni su lenguaje son los de un liberticida; más bien, son los de un liberal sombrío que prescribe un uso temperado de la fuerza.

El poder, según Pareto, es un lugar común de todas las actividades sociales, pues se genera en todas ellas como si se tratase de un proceso físico inexorable ${ }^{34}$. El poder como un hecho social $3 / 4 \sin$ los prejuicios morales de maquiavelistas y antimaquiavelistas $3 / 4$ se impone en toda visión de la sociedad que no excluya las nociones de jerarquía, la heterogeneidad de los ámbitos de la vida humana colectiva y la persistencia de la naturaleza humana. (1) En primer lugar, la jerarquía supone que la sociedad alcanza un punto de equilibrio en función de las relaciones de poder. Pareto sólo añadió un tanto de cinismo a su descripción de la corrupción de las elites burguesas, en vías de ser sustituidas por las elites socialistas. (2) La heterogeneidad, como terminología sociológica, es comparable a la noción weberiana del politeísmo de los valores ${ }^{35}$. Ahí está, en realidad, el corazón de su teoría del equilibrio: la discordia, la posibilidad de que choquen los intereses y surja el conflicto. Ortega y Gasset se refirió en La rebelión de las masas, casi en clave paretiana, a la quiebra del principio de lo diverso como una novedad. No le faltaba razón al filósofo 
madrileño, si bien no reparó en que aún en la homogeneidad átona del hombre masa puede arraigar el pluralismo valorativo, pues también la mediocridad del señorito satisfecho conoce la gradación del más y del menos. (3) Finalmente, con respecto al presupuesto metafísico de Pareto, Freund lo cifró en su creencia en la persistencia de la naturaleza humana. Pareto fue un filósofo a pesar suyo $o^{36}$.

La fuerza, según Pareto, ocupa un papel central en las relaciones sociales. Para él, la querella inagotable sobre si se debe o no se debe usar la fuerza carece de sentido. "De hecho, llegó a escribir, quien es favorable a la clase gobernante, si dice que reprueba el uso de la fuerza, en realidad reprueba el uso de la fuerza por parte de los sedicentes" ${ }^{\prime 37}$. La fuerza es necesaria hasta para instaurar un sistema jurídico que reniegue formalmente de aquella ${ }^{38}$. Aunque "en toda la historia aparecen el consentimiento y la fuerza como medios de gobierno"39, al ser imposible persuadir a todo el mundo y querer toda elite perpetuarse en el mando, el recurso a la fuerza es un imperativo para las clases rectoras. Los escrúpulos, la flaqueza y los buenos sentimientos hacen de la historia un cementerio de aristocracias, pues el poder no descansa y quienes lo reivindican tampoco. En este sentido, Freund equiparó la exposición teórica de la circulación de las elites, sometida a los ciclos del poder, y la teoría de la decadencia. "La originalidad de Pareto, decía, consiste en mostrar que la decadencia está estrechamente ligada al destino de la elite en una sociedad" ${ }^{\prime 0}$.

\section{GEORGE SIMMEL Y EL CONFLICTO COMO FORMA DE SOCIALIZACIÓN}

Las relaciones de Simmel con personas e instituciones señaladas de la sociología académica francesa tuvieron, durante algunos años, cierta fluidez. Aunque Durkheim le tenía por un psicologista, su revista L'Année sociologique le había publicado un artículo en 1897: Comment les formes sociales se maintiennent. Después de la Primera guerra mundial la obra del berlinés Simmel perdió el favor de los ambientes universitarios franceses. Así, fuera de un estudio de 1925 de Vladimir Jankélévitch, discípulo de Bergson, y otro, en 1935, de Aron, Simmel fue, durante mucho, un gran desconocido en Francia ${ }^{41}$. La situación contrastaba vivamente con su recepción en los Estados Unidos de América, sobre todo a través de la Escuela de Chicago y de Robert E. Park, alumno de Simmel en Berlín, en 1899. Curiosamente, después de la II guerra mundial, la sociología de Simmel volvió a Europa con un nuevo empaque américanisé, decía Freund ${ }^{42}$. No obstante, en Alemania, Italia y España nunca se le dio de lado. Valga como ejemplo de ello el recuerdo de la formidable veta simmeliana de la sociología de Ortega y Gasset $^{43}$.

Simmel, de aguda e inquieta inteligencia, fue un esteta además de sociólogo, lo que le distingue de los demás fundadores de la sociología. Reflexionó y escribió sobre las más variadas parcelas de la vida cotidiana: el erotismo y la coquetería, el amor y la muerte, la moda, etc. Su éxito como Privat Dozent le malmetió en el 
mundo académico y le alejó de los laureles universitarios. Aunque fue acusado de diletante por la pedantería erudita, la supuesta mundanidad y llaneza de muchos de sus escritos es todo lo contrario a la impremeditación.

La pluralidad temática de la obra de Simmel ha abierto numerosas vías a la sociología moderna. En una de sus obras más notables, en la que están reunidos sus estudios sobre las formas de socialización, hay in nuce varias sociologías particulares: la del conflicto, la del poder, incluso la de la pobreza ${ }^{44}$. También hay una sociología del número en las relaciones sociales, inspirada por la misma razón que acicateó a los sociólogos de las muchedumbres: el impacto de lo cuantitativo sobre las formas de la vida humana colectiva. Es la experiencia visual del "lleno", coetánea del desarrollo de la gran industria. O el hecho de las aglomeraciones, dicho con la literalidad de Ortega y Gasset ${ }^{45}$.

Simmel asentó las bases de dos concepciones complementarias de la sociología como disciplina científica. La primera es la sociología general, "principio heurístico que puede aplicarse útilmente a una infinidad de dominios diferentes del saber" ${ }^{46}$. Su objetivo es convertir la dialéctica entre el individuo y lo social en una especie de método genético aplicable a todas las disciplinas en cuanto que todos sus objetos científico están producidos por la vida ${ }^{47}$. La sociología formista o pura es distinta ${ }^{48}$. Según Simmel, "dada su característica fundamental, no se debería hablar de sociedad sino de socialización (Vergesellschaft). La 'sociedad', en ese caso, sólo es el nombre dado a un conjunto de individuos ligados entre sí por acciones recíprocas, razón por la que se considera como una unidad"49. Lo que Simmel denominó formas de socialización, es decir, "las diversas clases de acción recíproca" 50 , es el contenido de lo social, "la sociedad sensu strictissimo" ${ }^{51}$. La sociología formista, según Simmel, debe, pues, consagrarse al estudio de todas las formas de socialización, sin despreciar ninguna.

La renovación en Francia del interés por la sociología formista de Simmel debe mucho a la labor de sociólogos como Freund o Michel Maffesoli. La larga introducción de Freund a Sociologie et épistémologie, que recoge escritos de Simmel de los años 1890, además de su tratado póstumo Grundfragen der Soziologie, sigue siendo un punto de referencia sobre el sabio berlinés en la literatura especializada europea. Decía Freund que la piedra angular de la filosofía simmeliana es el dualismo: entre lo objetivo y lo subjetivo, entre la asociación y la disociación, entre la continuidad y la discontinuidad, entre la forma y la materia. Este pensamiento dualístico explica la importancia que da Simmel a la lucha. La lucha, decía el sociólogo alemán, "es un remedio contra el dualismo disociativo, una vía para llegar de algún modo a la unidad, aunque sea por el aniquilamiento de uno de los partidos" $"$. La caricia y la agresión son dos formas de la coexistencia humana, las dos caras de la misma sociabilidad. Es probable que los hombres tengan las mismas razones para amarse y para odiarse ${ }^{53}$. ¿Por que valorar distintamente las formas de sociabilidad cooperativa y las conflictivas? ¿No son unas y otras susceptibles de 
promover, en un agregado humano, las pautas que permiten hablar de sociedad o comunidad de hombres, y no de una mera coincidencia espacial y temporal de los individuos? La polemología de Freund está basada en estos pensamientos de Simmel. El conflicto, escribe el autor en su tratado sistemático Sociologie du conflit, es una relación social, pues sólo puede nacer a partir de la compresencia de otros (un conflit en peut naître que de la présence d'un autre ou d'autres) ${ }^{54}$.

\section{LOS CLÁSICOS DE LA SOCIOLOGÍA FRANCESA}

El dominio ejercido por la escuela durkheimiana en los medios universitarios franceses determinó probablemente el escaso reconocimiento por los especialistas de quienes no eran presentados en sociedad como sociólogos profesorales. Tal fue el destino de Gabriel Tarde y de Gustave Le Bon, juez y criminólogo el primero, médico y cronista científico el segundo. Personal e intelectualmente, Freund estuvo mucho más cerca de Le Bon y Tarde que de Durkheim, cuyo magisterio se vio perjudicado, a la larga, por la beatería de sus leales, acaso demasiado confiados en la objetividad que atribuía el maestro a los hechos sociales. Como en tantas ocasiones, el rigorismo propio de la manera universitaria de pensar, en lo que tiene de sectario, sólo ha servido para explicar, a posteriori, el error de una falsa ortodoxia que se arroga el derecho de prescindir de aquellos a los que se tilda de amateurs. Aunque hay ciertas dosis de heterodoxia en las sociología de Tarde y Le Bon lo que podría discutirse ampliamente, pues en realidad eran, por los temas tratados, tan contemporáneos de su época como los más reconocidos sociólogos, no hay en ellos ni un ápice de diletantismo. Dentro de Francia gozaron de cierto predicamento entre un público culto pero no especializado. Fuera, sin embargo, eran muy respetados por intelectuales, estadistas y científicos de toda clase.

Freund, recién incorporado a la docencia universitaria en Estrasburgo, comprobó que muchos de sus alumnos oían por primera vez aquellos nombres en sus clases de sociología. El profesor intransigente con las modas fue consciente de la sorpresa de su joven auditorio cuando exponía las ideas de Tarde y Le Bon. Algunos de sus temas, sumamente delicados para los años 60 "políticamente incorrectos", decimos ahora, tenían nombres que hacían temblar a los profesionales del sinistrisme. Simplificando mucho, y por utilizar una terminología algo desfasada, se trataba de escritores reaccionarios y temerosos de la democracia, es decir, antisocialistas. El doctor Le Bon lamentábase de la "transformación progresiva (de las muchedumbres) en clases directoras" ${ }^{\prime 5}$. Encontraba alguna relación entre el fin de las civilizaciones y la alteración de la competencia rectora, a la que por cierto no era ajena la evolución del socialismo hacia una nueva forma religiosa ${ }^{56}$. Tarde, por su parte, había escrito un libro de título singular que fascinó a Freund: L'opposition universelle. Essai d'une théorie des contraires. En sus páginas, mostró Tarde que su concepción del funcionamiento de la realidad, de la lógica social, está en los 
antípodas de la dialéctica hegeliana. "Contrariamente a ciertas interpretaciones de su pensamiento, decía Freund, me parece que ilustra la existencia de antagonismos irreductibles en la acción, al revés que las lógicas epistemológicas afectadas a la elaboración de una conciliación puramente teórica"s7. ¿Quién podría esperar que Tarde, contradictor del ensueño que reduce lo social a uno de sus componentes, cayese en gracia ante los lugartenientes del monismo del Diamat?

\section{LA TEORÍA FENOMENOLÓGICA Y EPISTEMOLÓGICA DE LAS ESENCIAS}

Freund aspiraba a clarificar el panorama de las ciencias humanas, término preferido a "ciencias sociales", especialmente el de la sociología, excluyendo todo prejuicio antimetafísico. En esencia, el estatuto de la sociología, en vísperas de su incorporación a los estudios universitarios, seguía siendo el mismo que forjaron los fundadores de la disciplina. La sociología de la sociología no podrá pasar por alto que los primeros sociólogos que se licenciaron o graduaron como tales, lo hicieron después de los años 1950. Ya se ha dicho aquí que Aron, Freund y tantos otros venían de la filosofía. Si se mira la nómina de los grandes sociólogos de principios de siglo se ve que Pareto era ingeniero y economista, o que Durkheim escribía sobre filosofía moral.

\section{EL TRASFONDO FILOSÓFICO DE LAS CIENCIAS HUMANAS}

Para Freund, siguiendo el modelo de la sociología general de Simmel, lo sociológico de la sociología se concreta en un punto de vista peculiar, capaz de ofrecer nuevas perspectivas a las demás ciencias. Del mismo modo que las distintas disciplinas se enriquecieron en la segunda mitad del siglo XIX con las aportaciones del nuevo saber histórico, 50 años después, la idea de que los fenómenos humanos pueden concebirse como producidos por la coexistencia humana en el sentido de la soziale Produktionsart de Simmel ${ }^{58}$, removió la estanqueidad en la que, finalmente, paró el historicismo. Con el tiempo, no obstante, el saber sociológico dio lugar a un nuevo reduccionismo: el sociologismo. Pero el sociologismo no es una ciencia, sino más bien una mentalidad cientificista, para la que todo lo humano es reducible a lo social. En cierto modo, el sociologismo estuvo inducido por la actitud intelectual antimetafísica de casi todos los fundadores de la sociología. Especialmente Durkheim, Pareto y Weber, pues Simmel constituye un caso aparte ${ }^{59}$. Aunque ninguno de ellos fue en rigor un sociologista, con la posible excepción del primero, sin embargo, sentaron las bases para que la sociología positiva y la positivista rompieran la continuidad de la experiencia humana sobre lo colectivo.

Freund consideraba un retroceso la generalización del positivismo en las ciencias humanas. Reconoció empero que, "según la experiencia que se tiene de la 
disciplina", existen tres maneras de abordar el fenómeno sociológico ${ }^{60}$. Por una lado, la forma ideológica, que utiliza y, en su caso, falsea la teoría con fines prácticos. Por otro, la forma positiva (l'approche positive), basada en la acumulación de datos y en la clasificación de las observaciones. Freund rechazó la primera y relativizó los logros de la segunda. La tercera manera de abordar el análisis de lo social es la filosófica. Esta fue la que el autor desarrolló por su cuenta y a contracorriente. El mundo de la vida, sobre el que tiende sus redes el pluriverso metodológico de las ciencias humanas, es un orden formado socialmente. La pregunta clave para un sociólogo filósofo consiste, entonces, en esta aparente banalidad: ¿cuándo puede decirse que una actividad es política, económica, religiosa o estética? ${ }^{61}$ La mayor ambición intelectual de Freund en el ámbito de la reflexión sobre los fundamentos del saber sociológico fue la de hacer aflorar sus fundamentos filosóficos y epistemológicos. Para ello desarrolló su propio lenguaje y sus propias categorías, pues las filosofías de la época no le parecían adecuadas para llevar a cabo sus investigaciones: ni el idealismo neokantiano, más o menos difuso, cuya concepción de la metafísica y la ciencia rechazaba Freund, ni las imposturas filosóficas de moda. La teoría de las esencias es el fruto de su esfuerzo ${ }^{62}$. Aunque inicialmente fue la respuesta del autor al desafío de la evolución de la sociología como disciplina teórica, la teoría de las esencias sintetiza los supuestos metafísicos, fenomenológicos y espistemológicos de todo su pensamiento.

\section{LA NOCIÓN DE ESENCIA}

La exposición de la teoría de las esencias requiere, lógicamente, aclarar previamente lo que entendía Freund por esencia (essence). Como noción epistemológica, la esencia es un instrumento que sirve para estudiar la parte del ser que no es naturaleza, es decir, las creaciones artificiales del hombre basadas, no obstante, en la naturaleza. Pero la esencia tiene también una dimensión fenomenológica, lo que puede suscitar algún equívoco a propósito de sus relaciones con categorías próximas como naturaleza, significación o cultura.

Con respecto a la naturaleza, la esencia se presenta como una manifestación específica del ser. En opinión de Freund, aunque la esencia preexiste como potencia o disponibilidad de las $\cos ^{6 s^{63}}$, no puede asegurarse a ciencia cierta el descubrimiento y despliegue de sus posibilidades. De este modo se entiende que la política, actividad descubierta por los griegos, sea una manera de afrontar las exigencias de lo político. La distinción de Aristóteles entre regímenes políticos y regímenes despóticos se apoya, en el fondo, sobre el carácter insuperable de lo político y la dimensión artística (y contingente) de la política, con la que el hombre pone coto a la "urgencia del vivir" Si por naturaleza se entiende lo que las cosas son como manifestación directa o inmediata del ser, la esencia "concierne a los entes elaborados intelectualmente o artificialmente, y formados por la creación o la producción humana" ${ }^{95}$. 
Tocante a la relación entre cultura y esencia, Freund decía que las formas que adopta la primera son fugaces, incluso en su acepción más extensa $3 / 4$ Kultur, Civilisation, mientras que la esencia permanece como el fondo inmutable de todas las épocas. La acumulación de todas las manifestaciones de la vida humana nunca agotará la noción de esencia, debido a que la originalidad creadora o destructiva de las generaciones futuras siempre tendrá algo que añadir ${ }^{66}$. Aunque lo político, lo religioso o lo estético son eternos lo que quiere decir que el hombre seguirá respondiendo a sus determinaciones mientras siga siendo lo que es, la política, la religión o el arte están sometidos, como todo lo humano, a su condición terminadiza y contingente.

La esencia también le sirve al autor para delimitar con claridad la noción de significación (signification), tomada en sentido filosófico y no lexicológico. Desde el punto de vista de la esencia, cada actividad humana es considerada según su lógica interna y el desenvolvimiento de sus elementos constitutivos. La significación, por su parte, hace referencia a las relaciones que las esencias mantienen entre sí. "La esencia, escribe Freund, se define por la aseidad, por su relación consigo misma, pero la significación se define por la alteridad, por la relación con lo otro" $" 67$. La historia muestra que las relaciones entre las esencias no son siempre necesariamente armónicas; también caben, según el momento y el lugar, la indiferencia y, por supuesto, un abierto enfrentamiento. Para Freund, el problema de la significación se resume en la idea de jerarquía, en el sentido de si es posible establecer un orden de prelación de las esencias, por encima de las valoraciones de los individuos, de las generaciones y de las épocas históricas.

La esencia, en suma, es la determinación de lo que pertenece a una actividad, su quididad. "La reflexión sobre la esencia, asegura el autor, consiste en un doble esfuerzo de identificación y de diferenciación de nociones, sin las que nos hundiríamos en la confusión. No es, por tanto, ni un juego gratuito ni una tarea ociosa" ${ }^{968}$. Sus ventajas son notables en el orden epistemológico. Concretamente, evita tener que plantearse la cuestión del origen histórico de las actividades humanas, pues en toda comunidad humana se han conocido la política, la economía y demás, en múltiples formas. Decía el antropólogo francés Pierre Clastres, apoyándose en una lectura un tanto parcial y extemporánea de Etienne de la Boëtie, que el hombre cayó en la política en algún momento de la historia ${ }^{69}$. Freund rechazó estos argumentos. ¿Para qué serviría, por lo demás, fechar ese tiempo fundacional?

La noción de esencia excluye el razonamiento en términos de una falsa causalidad, puesto que carece de sentido afirmar que una esencia, sea cual fuere, pudo engendrar a las otras en un pasado remoto ${ }^{70}$. Presuponer el carácter estructural de una esencia falsea su relación con las demás esencias. De este modo, la noción de esencia presupone la pluralidad de las esencias $y$, en consecuencia, la dialéctica de los contrarios ${ }^{71}$. 


\section{LA TEORÍA DE LAS ESENCIAS}

"La esencia determina la relación de una actividad consigo misma para comprender su lógica interna, en cuanto a su sustrato o antecedente (donnée); en cuanto a sus resultados o finalidad específica (finalité); en cuanto a las condiciones de su ejercicio o presupuestos (présupposés)" ${ }^{\text {"72 }}$. Con otras palabras, la esencia es el puente epistemológico y fenomenológico que permite distinguir entre lo político y la política, entre lo económico y la economía, entre lo estético y el arte, y así sucesivamente.

A continuación se exponen los aspectos más importantes de los elementos de la teoría de las esencias ${ }^{73}$.

\section{A.- El antecedente}

La reflexión sobre las esencias no está exenta del riesgo de caer en el artificialismo social, es decir, en el diseño de una actividad inexistente. Para evitarlo, Freund razonó en sentido contrario al utopismo social. El hombre, solía decir, es ya hombre desde un principio ${ }^{74}$, pero el fundamento in re de su naturaleza es la donnée. Esta noción, asociada muchas veces a la filosofía de Bergson, es el revulsivo epistemológico del constructivismo y del positivismo científicos. La donnée supone que hay algo que determina que el hombre sea inmediatamente un ser político, económico o religioso. Sin embargo, constituye el punto de partida no político, no económico o no religioso de los correspondientes dominios de la acción humana. En términos de causalidad, la donnée es el momento irreductible de toda regresión causal ${ }^{75}$.

Esa noción establece ciertas determinaciones que pesan sobre la acción humana, pero no es determinista. Todo lo contrario. La donnée no excluye la idea de libertad sino que la hace inteligible. No prefigura, por tanto, el futuro de la humanidad, que está abierto al arbitrio del hombre. En última instancia, su fijeza constituye la condición epistemológica de la comprensión del cambio histórico.

Los antecedentes son propios de cada esencia. Si las esencias, según Freund, son seis, los antecedentes son, así mismo, seis. La donnée de lo político es la sociabilidad (sociabilité); la de lo económico, la necesidad (besoin); lo de lo religioso, la muerte (mort); la de lo moral, la conciencia (conscience, Gewissen); la de lo estético, el gusto (gô̂t) y la de lo científico, el conocimiento (connaissance) $)^{76}$.

\section{B.- Los presupuestos}

Con los presupuestos, el peso de la meditación freundeana pasa de lo metafísico a lo fenomenológico, pues están, por decirlo así, en la divisoria de lo político y la política o de lo económico y la economía. Freund los definió como "evidencias que se imponen a priori y que encontramos necesariamente bajo unas formas históricas variables, mediante las cuales una esencia se manifiesta concretamente" ${ }^{\text {"77 }}$. Se trata, por 
tanto, de una especie de principios formales de la acción, que permiten discernir cuándo es económica, política, etc. En este sentido, pueden fundamentar también una praxeología.

Freund formalizó los presupuestos como pares de conceptos antagónicos, inspirándose previamente en la experiencia milenaria de los hombres. Sólo mediante la reflexión sobre la historia se puede poner de manifiesto la "condición constitutiva" de las esencias. ¿Por qué las evidencias apuntan en un sentido o en otro? Eso, escribe el autor, "no lo sabemos y tal vez no le podamos encontrar ninguna justificación"78. Para conjurar eventuales críticas, Freund recalcó en numerosas ocasiones que lo presupuestos ni condicionan ni predeterminan estilos o formas de vida concretos $^{79}$. La teoría de las esencias no sirve para buscar soluciones a los problemas contemporáneos. No se trata de esbozar el régimen mejor o el arte perfecto, sino de reflexionar sobre si las distintas instituciones o las acciones humanas son coherentes con la esencia de la que dependen. Por citar sólo algunos, los presupuestos de lo político serían mando-obediencia, público-privado y amigo-enemigo; y los de lo económico útil-perjudicial, escasez-abundancia y señor-esclavo.

\section{C.- La finalidad y el medio específico}

En L'essence du politique Freund distinguió tres nociones próximas en apariencia: los fines generales de la acción humana (fins), las finalidades específicas de las esencias (buts spécifiques) y los objetivos de las actividades humanas (objectifs). La distinción es importante por dos razones. En primer lugar, evita confundir las metas particulares de cada actividad humana con fines o anhelos del orden escatológico, tales como la emancipación universal o la paz perpetua. Estos fines últimos trascienden la reflexión fenomenológica, debido a su naturaleza indeterminada (ison fines en sentido estricto o, más bien, valores?). Sin perjuicio de que puedan orientar las conductas individuales, carecen de toda especificidad praxeológica (¿con qué medios se puede promover el amor entre todos los seres humanos?). En última instancia presuponen que "el hombre es el hermano del hombre y que existe una humanidad"

En segundo lugar, la distinción permite diferenciar, en el orden teleológico, las distintas finalidades de cada esencia. En este sentido, la finalidad específica de una esencia es la meta que el hombre persigue, como ser inmediatamente político, religioso y demás. Los objetivos están subordinados a la finalidad específica. El autor los definió como "la sustancia material de una acción empírica" que aspira a realizar el fin de las esencias in concreto $^{81}$.

Para Freund, los fines de las esencias son los siguientes:

1. El Bien Común es el fin de lo político.

2. El bien-estar, de lo económico.

3. Lo absoluto, de lo religioso.

4. Lo verdadero, de lo científico.

5. Lo bello, de lo estético.

6. Lo bueno, de la ética. 
La meditación sobre las esencias estaría incompleta, al menos desde la óptica praxeológica, si los respectivos fines específicos no hallasen correspondencia en un medio (moyen) singular, propio de la esencia en cuestión y no sustituible por otros medios o por una combinación de los mismos. Los medios propios de cada actividad son estos ${ }^{82}$ :

1. La fuerza es el medio de lo político.

2. El trabajo, de lo económico.

3. El culto y la oración, de lo religioso.

4. La investigación, de lo científico.

5. La imitación, de lo estético.

6. En cuanto a lo ético, el autor considera que no tiene un medio específico, pues "la moral consiste en la manera en que nos servimos de los medios de las otras actividades, con la voluntad de realizar su fin propio" ${ }^{83}$.

\section{D.- Las dialécticas}

¿Por qué seis esencias y no cuatro, cinco, doce o ninguna? "Elegí seis actividades, decía Freund a Blanchet en L'aventure du politique, porque una actividad originaria considerada como una esencia se basa en una donnée de la naturaleza" ${ }^{\$ 4}$. ¿Cuál es entonces la naturaleza del derecho? ¿Es una esencia o una actividad secundaria, sin lugar en el reducido núcleo de las actividades humanas fundacionales? ¿Qué sucede con el resto de actividades de la compleja urdimbre de la acción social?

En su meditación sobre la vida humana colectiva, que abarca muchos puntos de vista (ontológico, fenomenológico, praxeológico), el autor se convenció de que únicamente existen seis esencias, id est, seis actividades autónomas e irreductibles las unas a las otras. Ahora bien, las demás actividades también pueden ser definidas en su esencia, mas únicamente en el sentido de aquello que les es propio y característico. Estas esencias secundarias, como Freund las llama en algún lugar ${ }^{85}$, se caracterizan porque las esencias primarias constituyen su donnée. Es decir, para el autor, las esencias secundarias sólo pueden ser concebidas si se presupone la existencia de las primarias, de las que dependen. La noción epistemológica que las denomina es "dialéctica" (dialectique).

Las dialécticas tienen un papel mediador entre las esencias originales. Los antagonismos de la vida no sólo se refieren a las contradicciones que indisponen a unos hombre contra otros. Hay un antagonismo interno en las esencias, que se manifiesta en la tensión entre sus presupuestos constitutivos. Los pares amigoenemigo, inmanencia-trascencencia o cualidad-cantidad son una fuente inagotable de discordancias. Freund fue adversario de la mentalidad progresista que piensa la realidad como un proceso que tiene tres momentos, en el último de los cuales se armonizarían los dos anteriores. El autor denominó dialéctica antitética (dialectique antithétique) a la dialéctica propia de los presupuestos de las esencias ${ }^{86}$. 
Existe otra forma de la dialéctica, la antinómica (dialectique antinomique), que Freund aplica a las tensiones que se producen entre las distintas esencias originales. En virtud de sus respectivos fines específicos, es probable que sus relaciones no siempre sean pacíficas. Lo que conviene a lo político no siempre es lo mismo que lo que conviene a lo económico o a lo científico. La dialéctica antinómica da, pues, razón de la mediación entre las esencias. El juego de las dialécticas es infinito, y Freund sólo trató sistemáticamente de unas pocas. En algunos casos, es tanta su especificidad que pueden pasar por esencias originarias. Como en el caso de lo pedagógico, de lo social (o cuestión social) ${ }^{87} \mathrm{y}$, sobre todo, del derecho o, más bien, lo jurídico (le juridique) ${ }^{88}$.

\section{EL ESTANCAMIENTO DE LA SOCIOLOGÍA REVOLUCIONARIA}

La sociología contemporánea, al convertirse en una sólida disciplina académica, ganó rigor científico pero perdió la fuerza y la frescura de los tratados clásicos. Junto al asentamiento de las investigaciones de sesgo positivista, durante los años 50 y 60 irrumpió con fuerza una sociología revolucionaria, que quiso hacer tabla rasa con lo que no se ajustaba a sus esquemas. Su objetivo último mezclaba en proporciones variables lo científico y lo ideológico. Freund estaba en contra de la ideologización de la sociología. Según su parecer, "ser un teórico de la sociedad no significa que haya que convertirse en un utopista social" $"$.

El sociólogo Maffesoli, a quien Freund tenía en gran estima, subrayó hace algunos años la conveniencia de alejarse "de la obsesión política que parece ser el nec plus ultra de todo progreso teórico para muchos sociólogos" $"$. Estas palabras resumen muy bien la preocupación freundeana por la deriva de la ciencia sociológica. La cuestión estriba en si puede aceptarse el sacrificio de la cientificidad de una disciplina a los valores o a la ideología personal del investigador, pues este tipo de actitudes destruyen la continuidad del saber, para la que nada es más pernicioso que la moda intelectual de distraer la verdad ${ }^{91}$. Constituye una terrible paradoja de nuestro tiempo que el honor de ciertos sabios no haya sufrido menoscabo al desvelarse que pusieron en circulación una falsa historia, una falsa ciencia social, etc. El "dejarpasar-todo" contemporáneo denuesta, sin embargo, a quienes se han negado a poner el saber científico al servicio de actividades o intereses extracientíficos, sobre todo al servicio de ciertas concepciones ideológicas de la política y la economía. Por eso, mientras que la obra de los verdaderos sabios es tildada de reaccionaria, muchas falsificaciones se benefician del guiño de complicidad del Establishment o cotarro ${ }^{92}$.

Es posible que la opinión de Freund sobre la sociología revolucionaria le parezca a los sociólogos de la última generación propia de otra época, pero aunque han cambiado los términos del problema denunciado por el autor, el fondo sigue siendo el mismo: la perspectiva ideológica de la investigación sociológica (l'abord idéologique de la recherche sociologique) es un elemento extraño en el cuerpo de 
la ciencia sociológica ${ }^{93}$. La crítica freundeana se inspira en su reflexión personal sobre el statutum epistemológico de la investigación sociológica. Sus conclusiones, aunque no están elaboradas sistemáticamente, se dejan traslucir en muchos de sus escritos. Lo más destacable de su refutación de la sociología militante o comprometida se puede resumir en el sesgo justificativo que, en su opinión, imprime la ideología en el método científico, y en la concepción del orden social.

\section{CRÍTICA DE LA IDEOLOGIZACIÓN DEL MÉTODO CIENTÍFICO}

El objetivo de la perspectiva ideológica, una de las tres vías recurrentes de la investigación sociológica, constituye la justificación de los a priori subjetivos del investigador, sean estos de índole política, religiosa o económica. Freund escribió que "lo importante para la ideología no es la lógica interna de la investigación, sino la capacidad del pensamiento para justificar el sentido de una acción determinada" ${ }^{94}$. Expresado de otra forma, lo que el sociólogo-reformador social busca por esta vía no es cualquier afirmación válida y limitada a las condiciones de la investigación científica, sino razones que verifiquen y autoricen determinadas pasiones o un engagement abstracto. Esta pseudociencia tiende a ofrecer visiones simplistas de la realidad, despreciando la heterogeneidad de los intereses, de los conflictos y de las coincidencias que presiden las relaciones humanas. El determinismo monocausal todo es economía, todo es poder, todo es represión, etc., sólo sirve para movilizar a la gente. El prestigio de las interpretaciones reduccionistas y logicistas de la realidad es, no obstante, uno de los signos de la época moderna.

La fabricación de utopías en sociología no es rechazable en sí misma. En ocasiones, este tipo de representaciones de lo imaginario han contribuido a reavivar el espíritu de alguna ciencia, marcando en su evolución un punto de inflexión. El pensamiento utópico puede entrañar empero algunos riesgos y debe ser rechazado cuando hace las veces de ideología y se convierte en el espíritu director de toda investigación o, lo que es lo mismo, cuando exige del científico la impavidez ante los hechos que, en otras condiciones de mayor libertad intelectual, desautorizan por sí solos una teoría que falsifica la realidad.

Para la sociología contemporánea, los años 60 y 70 fueron bastante decisivos. No en vano, el prestigio y la popularidad que entonces alcanzó todavía se mantenía en fechas recientes. Coincidiendo en Europa con la reviviscencia intelectual de los marxismos, la ciencia de Weber y Simmel, de Pareto y Durkheim, viose impregnada por misiones que trascendían su finalidad específica. En palabras de un rigurosísimo especialista, "la sociología de los años 60 y 70 en Francia sobre todo, contribuyó a menudo a conferir a ciertas quimeras ideológicas la autoridad de la ciencia"95. La ideologización de este campo del saber se operó, pues, sin demasiadas resistencias. Salvo contadas excepciones, las salidas lógicas se encontraron, bien en la racionalización de anhelos utópicos, para hacerlos coherentes 
con los designios del pouvoir indirect ideológico, bien en la destilación de los consejos y reglas prácticas que reclamaba la aparente neutralidad tecnocrática. En la práctica, las dos salidas se mostraron plenamente compatibles en la figura de muchos expertos. Estos últimos, adoptando el viejo papel de los consejeros de príncipes o sirviendo, simplemente, a providentes planificadores sociales, desplegaron a placer el seductor panorama de las sociedades ideales.

\section{CRÍTICA DEL CONSTRUCTIVISMO SOCIAL}

El proceso de ideologización de las ciencias humanas se vio favorecido, además, por la generalización de una forma abstracta de concebir la política y, por tanto, la sociedad y la convivencia humanas. La difusión de la mentalidad abstraccionista ${ }^{96}$ ha promovido todo tipo de representaciones de la sociedad como producto de un obrar consciente del hombre. Este artificialismo social está lleno de consecuencias. Por un lado, ha contribuido a desplazar la noción de naturaleza del lugar privilegiado que le habían reservado la filosofía clásica y, así mismo, la ciencia, desprendida de la matriz filosófica original. La sustitución de lo natural por el artificio no ha sido, sin embargo, ni lineal ni evidente por sí misma. En este sentido, "se admite, escribe Freund, que el hecho de vivir en sociedad responde a una exigencia de la naturaleza, pero al mismo tiempo se sostiene, bien apoyándose en una concepción dialéctica del devenir, bien en una concepción de la madurez progresiva de los individuos, que la eliminación a largo plazo de los conflictos pertenece al orden de las cosas" ${ }^{\prime 97}$. Según el autor, los efectos de este trastrocamiento se ponen de manifiesto al considerar el papel dominante de la técnica en el mundo moderno.

El artificialismo social, confiando en la dominación de la tecnología, ha abierto a los hombres inmensas posibilidades. Estas expectativas no son de ahora. El normativismo de la Física social de Comte presuponía el primado del artificio para restaurar el poder espiritual o, dicho de otra manera, para reconstruir el orden social. ¿Acaso no están la ciencia y su potencia tecnológica en el corazón mismo de las ideologías revolucionarias modernas? En la época de los planes quinquenales se difundió a todos los vientos la consigna "electricidad y koljoses", como la clave de la bóveda social. Ahora, aunque en otros términos, este tipo de mistificaciones siguen haciendo camino ${ }^{98}$.

Los saberes sociológicos se resintieron con la confluencia de técnica y utopismo, situación de la que no se retorna sin esfuerzo. Freund siempre mantuvo un criterio uniforme. Éste puede servir como colofón de su crítica del constructivismo, como actitud mental y como práctica pseudocientífica: "el papel de la sociología, decía, no es construir la sociedad utópicamente perfecta. Es un objetivo que la trasciende, a menos que se transforme en política o, más bien, en una doctrina política"99.

El constructivismo social y la ideologización de algunos saberes permiten reunir en dos grandes familias las teorías sociológicas afectadas por la transformación de las actitudes intelectuales contemporáneas. Ambas tienen en común la pretensión 
de alterar el conjunto de las estructuras e instituciones sociales y, así mismo, la sustancia de las sociedades (la substance même des sociétés historiques) ${ }^{100}$. Sin embargo, las teorías de la contrasociedad (théories de la contresociété) propugnan la edificación de una sociedad inédita y mejor que cualesquiera de las conocidas. En cambio, las teorías de la antisociedad (théories de l'anti-société) postulan un modelo de coexistencia humana que sería una cosa distinta de una sociedad. La sociología de Marx es, probablemente, el ejemplo más notable de una teoría sociológica de la contrasociedad. Marx, que pensaba con las mismas categorías del resto de críticos sociales de su tiempo, estaba también imbuido, como muchos de ellos, de las ideas constructivistas, que señalaban a las ciencias sociales la tarea de servir a la transformación del mundo. En este ambiente, es comprensible que las condiciones de validez del saber se releguen a un segundo plano en beneficio de su intervención eficaz en la realidad histórica concreta. No se trata tanto de ser objetivos cuanto de tener poder (Macht) para poder implantar la contrasociedad ${ }^{101}$. En realidad, la lógica de este razonamiento es aplastante: una sociedad que no existe en ningún lugar rechaza todo examen científico, consecuentemente, la verificación de sus hipótesis depende de la relación de fuerzas de sus partidarios.

\section{HACIA UNA SOCIOLOGÍA CIENTÍFICA DEL CONFLICTO}

La ambición teorética marcó el pensamiento de Freund, quien se vio impulsado en un momento dado de su trayectoria intelectual, a desarrollar una sociología particular, la Polemología (polémologie). De su dedicación a esta rama de la sociología han perdurado, además del Instituto de Polemología de Estrasburgo, su segundo libro en importancia, titulado, tal vez por razones editoriales, Sociologie $d u$ conflit, en el que desarrolla el estatuto científico de la polemología. La apuesta intelectual de Freund tuvo dos grandes enemigos, que ni siquiera hoy han podido ser batidos: por un lado, la consabida ideologización que minó las ciencias humanas, $\mathrm{y}$, por otro, la mala prensa de los escritores que no ocultan la trascendencia del conflicto, ni velaban sus consecuencias en nombre de una temática más popular, como la paz o el consenso.

\section{FREUND EN LA DISPUTA DE LA POLEMOLOGÍA Y LA IRENOLOGÍA CIENTÍFICAS}

A continuación se exponen las vicisitudes de la sociología del conflicto en los años 50 y 60, pues la polemología de Freund se fraguó en el contexto espiritual y académico de esa época. Después se hace mención de las teorías de dos importantes sociólogos contemporáneos, Johan Vincent Galtung y Gaston Bouthoul, quienes representan con gran fidelidad la irreductibilidad entre la escuela irenológica de la sociología de la paz y la escuela polemológica de la sociología de la guerra. Freund 
pertenece a ésta última. No obstante, es de notar que aun cuando hizo causa común con Bouthoul contra el sesgo ideológico de la irenología, su concepción de la polemología es más amplia que la de su colega y amigo. En el sentido que le dio Bouthoul, la polemología es una sociología de las guerras; para Freund, en cambio, la polemología es una sociología del conflicto ${ }^{102}$.

En los cenáculos sociológicos españoles de los años 70, todavía se decía que "el marxismo es históricamente la principal de todas las doctrinas conflictivistas" 103 . Parafraseando a Freund, cualquier investigador o enseñante con un barniz del historicismo marxista de la lucha de clases, podía pasar, en las aulas de entonces, por un eminente teórico de la sociología del conflicto ${ }^{104}$. Operábase así, por enésima vez, la recepción tardía en España de tantos lugares comunes de la intelectualidad europea, mayormente francesa ${ }^{105}$. En cualquier caso, ni en Francia, ni en España, ni en otros países se reparó, salvo contadas excepciones, normalmente ajenas a los ambientes sociológicos académicos, que las posibilidades del marxismo como ciencia de los conflictos (la lucha de clases) eran menguadas; sobre todo teniendo en cuenta su fondo escatológico. No obstante, en un libro precursor de Ralph Dahrendorf, Las clases sociales y su conflicto en la sociedad industrial (1957), se estableció una separación coherente entre lo filosófico y lo sociológico del marxismo de Marx, evaluándose, así mismo, sus mistificaciones. Aunque Dahrendorf ha sido criticado en ocasiones por su supuesto "imperialismo panconflictivo", su meta científica consistía en dotar a la sociología dinámica de unos instrumentos adecuados para poder explicar el cambio social por vías distintas al armonicismo típico de la sociología americana de la época. Ese libro de Dahrendorf ha corrido, inmerecidamente, la suerte de parte de la escolástica marxista. Sin embargo, la renovación del interés por el conflicto social, tal vez producto del abandono de la política, le debe mucho.

En un primer momento, las investigaciones sobre el conflicto tuvieron un sesgo militante y profético, pues no siempre se observaron las exigencias propias de una disciplina científica. Vale la pena contrastar aquí el punto de vista divergente de la irenología y la polemología. Galtung, fundador en 1959 del International Peace Research Institute of Oslo, Ekkehart Krippendorff y Herman Schmid, destacados especialistas alemanes de la Friedensforschung, de inspiración marxista, son representativos de la primera; Bouthoul, fundador en 1954 del Institut Français de polémologie, y Freund son los máximos exponentes de la segunda. Mientras que el objeto científico de la primera escuela es la paz, el de la segunda es la guerra o el conflicto. En su momento fundacional, ambas escuelas respondían a los mismos estímulos de una realidad sobre la que pesaban los daños materiales y, sobre todo, morales o espirituales infligidos por la II guerra mundial. Sin embargo, mientras que el magisterio de los Peace Researchers se benefició del prestigio social de las bellas intenciones, los estudios polemológicos fueron tachados de conservadores, incluso de reaccionarios. Pero ¿quién diría que un investigador consagrado al estudio 
de la bacteria Acinetobacter baumannii es partidario de las infecciones intrahospitalarias y de la morbilidad que inducen en los pacientes? Nadie de buena fe. Sin embargo, a quienes estudian sin anteojeras ideológicas las guerras se les presume una propensión belicosa, militarista o polemógena de la que, al parecer, estarían exentos quienes se decantan por el estudio de la no-violencia, el consenso y la paz ${ }^{106}$.

\section{A) Refutación de Galtung}

Galtung, sociólogo noruego y cosmopolita, ha dado empaque científico al idealismo pacifista occidental. Es autor de una importante serie de artículos y libros consagrados a esta temática. Su gran virtud, como ha señalado Freund, es la asociación de los fenómenos de la violencia y el conflicto ${ }^{107}$. Su prioridad, no obstante, es el estudio de la paz. La objeción de fondo que pone Freund a sus desarrollos teóricos es que concibe la paz como un moralista, haciendo de ella "una construcción en la que predominan los buenos sentimientos"108.

Galtung ha definido la violencia como "la causa de la diferencia entre lo potencial y lo efectivo, entre aquello que podría haber sido y aquello que realmente es" ${ }^{109}$. Dejando a un lado la relevancia científica de esta definición, que liga un juicio inverificable y moralizante (la representación de un mundo armónico) con una constatación empírica (un mundo en el que existen los antagonismos y las inconsecuencias en el proceder humano), el problema estriba en que la sociología particular de Galtung conduce automáticamente a la impugnación de la realidad cotidiana y al activismo, es decir, a la militancia en pos de una causa extracientífica. En contraste, Freund no fue, desde luego, el tipo de intelectual que cree que la disciplina que cultiva es la redentora del hombre. Tenía muy claro que atribuir a la ciencia una misión ideológica o escatológica es contrario a la esencia de la misma ciencia ${ }^{110}$. Según Galtung, existe una violencia que llama estructural, por oposición a la violencia personal o directa, en la que no hay una relación visible entre sus efectos y las supuestas causas que el sociólogo le atribuye. Se trata de violencia latente que, siempre según Galtung, se da en todas las sociedades. "Cuando un marido golpea a su mujer tenemos ante nosotros un caso claro de violencia personal". Sin embargo, "si un millón de maridos mantienen a un millón de mujeres en la ignorancia nos las habemos con una violencia estructural"111. "La tesis de Galtung, comenta, empero, Freund, es típica de un mentalidad dominante actualmente en ciertos ambientes intelectuales. Se le da al concepto de violencia una extensión tal, que ya no se sabe ni lo que es ni lo que designa, ya que se la equipara bajo cuerda con nociones tan diferentes como la opresión, la represión, la dominación, la manipulación, la influencia, la autoridad, etc"112.

Para el sociólogo noruego todo puede ser violencia estructural, incluso los terremotos y otras catástrofes naturales. ¿Qué sucede, se pregunta, cuando "un orden social permite que algunas personas vivan bien, en casas sólidas y consistentes, mientras 
otras viven en barracas que se derrumban al primer temblor de tierra y matan a sus habitantes"? La respuesta le parece inequívoca: "aunque el desastre natural sea inevitable, el impacto social diferencial hubiera podido evitarse. Esto puede justificar, ciertamente, la utilización del término violencia estructural aplicado a esos niveles diferenciados de vivienda" ${ }^{113}$. Al comentar estas teorías en Sociologie du conflit, Freund se preguntaba si no sería también violencia la relación entre padres y hijos o, incluso, la del niño de pecho con su madre. Hay dos formas de anular la significación de la violencia, una de ellas es hacer creer que nada es violencia, la otra, en la línea de Galtung, que todo es violencia ${ }^{114}$. Al final, con estas premisas no es posible discernir lo esencial en la noción de conflicto. Tampoco en la de paz.

Para Galtung la paz es la ausencia de guerra o, como él dice, la ausencia de violencia personal. Ésta es, sin embargo, una concepción negativa. La lógica de su investigación le lleva a enunciar una definición positiva de la paz. La paz positiva o ausencia de violencia estructural es equiparable, en su opinión, con la justicia social como "condición definida positivamente (distribución igualitaria del poder y de los recursos)"115 ... La cuestión es si el Peace Research o la Friedensforschung pueden pretender la emancipación de la humanidad y al mismo tiempo reivindicar el estatuto de ciencia. Lo más grave de esta actitud intelectual es que, como dice Freund, "los teóricos de la eliminación de todo conflicto alimentan una hostilidad o, al menos, una cierta desconfianza con respecto a la actividad política, como si fuese un asunto alienante e impuro" 116 .

\section{B) Emulación de Bouthoul}

La repulsa mental a pensar la guerra se generalizó después de la II guerra mundial. Nadie estaba entonces para guerras, como dice Bouthoul en el prefacio de su Tratado de polemología. Pero el acuñador del neologismo polemología no se dejó llevar por la corriente y, "esperando dar ejemplo", fundó en 1945 el primer instituto dedicado al estudio de la pazy la guerra. El Institut Français de Polémologie subsistió sin apenas recursos hasta que cambió la actitud de la opinión pública. Aunque su iniciativa encontró eco en los Estados Unidos de América, en Inglaterra, en Alemania o en Noruega, fue más bien con una óptica más irenológica que polemológica. Finalmente, su ejemplo cundió sólo en Holanda e Italia ${ }^{117}$.

Freund, amigo personal de Bouthoul, a quien dedicó su libro Utopie et violence, atribuía a su compatriota el mérito de haber dado impulso, casi en solitario, a una nueva forma de abordar el estudio de los conflictos, "fuera de toda ideología u opción política, pacifista o de otro tipo". Por eso, se reconoció en el espíritu que animaba el pensamiento de Bouthoul. Este último solía repetir que si se quiere la paz, se debe conocer la guerra. El irenismo, ciertamente, se contenta en ocasiones con declaraciones pacifistas y condenas de la guerra o de lo militar. Por eso les desconcierta que se sugiera que los fines de la paz y de la guerra son los mismos, o 
que se demuestre que el pacifismo es polemógeno "una de las armas más eficaces de la guerra psicológica" ${ }^{118}$. Con respecto a esto último, no hay que descontar que el estalinismo se hizo portavoz del pacifismo internacional. Una cosa es ser pacifista, lo que no excluye que se pueda declarar una guerra en nombre de la paz, y otra cosa es ser pacífico o manso en el sentido de las Bienaventuranzas ${ }^{119}$.

El pensamiento de Bouthoul no es gratuito. Presupone, como ha recordado Freund, un profundo desasosiego intelectual: ¿por qué la guerra y la violencia fascinan tan apasionadamente a quienes desean la paz? ${ }^{120}$ Bouthoul vio en este sentimiento una suerte de sustitutivo de lo religioso: "al debilitarse las creencias religiosas, la guerra se ha convertido en la fuente más intensa de las emociones colectivas. Considerarla como un fenómeno social ordinario, desacralizarla, en suma, era una actitud que suscitaba una hostilidad inconsciente y generalizada"121. En cualquier caso, la marginación de los estudios científicos sobre las guerras está basada en la errónea creencia de que la guerra es la guerra y que es de suyo evidente, sin mediación posible de la inteligencia. ¿Qué razón había, se preguntaba Bouthoul en el prefacio citado, para que "la naturaleza nos hubiese ofrecido, en una excepción única, la comprensión inmediata e intuitiva de la guerra, mientras que nos la ha negado para todos los demás fenómenos, tanto biológicos como sociales". Pero hay otras suposiciones que dificultan también los progresos de la polemología. El autor se refirió, por ejemplo, al ilusionismo jurídico, que presume que las guerras son algo patológico y erradicable, que deben quedar reservadas a la imaginación y habilidad de los juristas. Ahora bien, en el caso de que los jusinternacionalistas tuviesen razón, ¿cómo empezar a legislar sobre lo que ni se conoce ni se estudia? Otras rémoras de la disciplina, no menos importantes, son la obsesión terapéutica de muchos sociólogos y la vía del menor esfuerzo, que se pliega al fatalismo de la inexorabilidad de las guerras ${ }^{122}$.

En la elección por Bouthoul de la guerra como pilar de sus investigaciones, pesaron sus preconcepciones filosóficas y metafísicas acerca de la naturaleza humana, la sociedad y los cambios históricos, pero también un motivo práctico: las manifestaciones empíricas del fenómeno bélico son más notorias y mensurables que las de la paz. Ello no quiere decir que no tomase en consideración el otro gran hemisferio de su disciplina, la irenología científica, distinta, por tanto, del pacifismo ${ }^{123}$. Bouthoul no pretendía pasar por un faiseur de paix, pero confiaba en que los progresos del estudio científico de las guerras conducirían a un verdadero pacifismo funcional ${ }^{124}$. "O la bomba, o la polemología"125.

El programa de investigaciones y de la disciplina de Bouthoul abarca, a grandes rasgos, la siguiente temática:

1. En primer lugar, el estudio de las estructuras o factores que alientan en el fondo de la agresividad colectiva (técnica, economía, demografía, mentalidades) ${ }^{126}$.

2. En segundo lugar, el estudio de las causas presumidas de las guerras. Al menos como regla epistemológica, resulta de gran utilidad distinguir entre éstas 
(las causas propiamente dichas de las guerras) y las causas ocasionales y motivos, que se refieren normalmente a las diferencias inmediatas y aparentes que desencadenan las hostilidades ${ }^{127}$.

\section{POSIBILIDADES Y ALCANCE TEÓRICOS DE LA POLEMOLOGÍA SEGÚN FREUND}

Al comparar las concepciones de la polemología de Bouthoul y Freund puede apreciarse que la del primero tiene un significado más restringido. Para Bouthoul la polemología es sobre todo una sociología de las guerras. Él mismo ha definido el objeto de su disciplina como el estudio de los conflictos que adoptan la forma de un homicidio organizado (homicide organisé), es decir, una lucha armada y sangrienta entre grupos organizados, limitada en el tiempo y en el espacio y sometida a unas reglas jurídicas particulares, extremadamente variables según el lugar y la época ${ }^{128}$. Freund, en cambio, le atribuyó a la polemología un contenido más amplio. Según sus propias palabras, se trata de la "ciencia del conflicto en general (la science du conflit en général), es decir, no sólo una ciencia de la guerra y la paz, sino de todo conflicto, lo mismo político que económico, religioso, social o de otro tipo" 129 . En este sentido, la polemología se ocupa, por tanto, de las huelgas y las revoluciones, del compromiso y la paz. En última instancia, ese esfuerzo suyo persigue la regeneración de la sociología, reuniendo en el marco de su disciplina "las diversas investigaciones que tienen por objeto el análisis de los conflicto, para mostrar el interés de este tipo de estudios y darles un impulso nuevo y coherente"130.

La gran aportación de Freund a la sociología particular del conflicto es el tratado sistemático Sociologie du conflit. La elaboración teórica de la noción de conflicto lo hace equiparable, salvando distancias, al libro I de Vom Kriege, de Clausewitz. Lo cual, ciertamente, dice mucho en favor del sabio francés, pero aún más, si cabe, del alemán, pues no hay que olvidar que era un militar de carrera. Freund forjó un concepto unívoco del conflicto, ordenando después en torno suyo toda la temática polemológica. Su caso es único, tanto por la originalidad del esfuerzo como por el rigor científico, si bien no puede decirse que su línea de pensamiento no cuente con ilustres antecedentes: Clausewitz, Simmel, Schmitt y Aron ${ }^{131}$.

\section{PRESUPUESTOS DEL ESTATUTO CIENTÍFICO DE LA POLEMOLOGÍA}

El pensamiento polemológico de Freund responde a dos objetivos básicos. El primero de ellos tiene que ver con una dificultad teórica que se le presentó al desarrollar sus investigaciones sobre la conflictividad propia de las modernas sociedades industriales (société conflictuelle o industrielle Konfliktgesellschaft). Después de haber reunido abundante material de investigación sobre los aspectos polemógenos 
de las sociedades industriales, Freund cayó en la cuenta de que "un análisis consagrado a los diferentes conflictos que sacuden las sociedades contemporáneas exige que se explore previamente de forma sistemática la noción central o axial de conflicto. ¿Cómo desarrollar una sociología de la sociedad conflictiva o, si se quiere, de la sociedad de los conflictos, si no se dispone del útil conceptual determinante de una sociología del conflicto?"132. La elaboración del conflicto como noción central de la polemología responde, pues, antes que nada, a una pura exigencia de rigor científico.

El segundo de los objetivos mencionados tiene que ver con el desarrollo de los temas tratados o esbozados en L'essence du politique, en particular con la ampliación de las reflexiones sobre la paz y la guerra. Sociologie du conflit ofrece, en este sentido, un desarrollo mucho más matizado de las tesis originales ${ }^{133}$. Se establece, por ejemplo, que tanto la lucha como el combate son dos especies del conflicto, extremo este que había quedado oscurecido en La esencia de lo político ${ }^{134}$. Pero lo más importante es, con todo, el refinamiento del análisis de las relaciones entre la política y el conflicto, acompañado de una sugestiva síntesis de la significación de la política en relación con el resto de actividades humanas. Es precisamente la conexión con la Filosofía Política o con la teoría de lo político, como prefieren los escritores italianos, lo que acrecienta el valor de Sociologie du conflit, un libro muy riguroso y, sin embargo, nada academicista.

\section{LA RELACIÓN ENTRE LA TEORÍA DE LO POLÍTICO Y LA TEORÍA DEL CONFLICTO}

Si se analiza con algún detenimiento la concepción de la guerra expuesta por Bouthoul en el Tratado de polemología, se puede comprobar que está condicionada por la ausencia de una reflexión sobre la política y, en consecuencia, sobre la finalidad específica de la guerra. Resulta muy significativo que en este libro tan sólo se dedique un breve apartado al sentido político que tiene la actividad bélica. De hecho, Bouthoul se limita a presentar una tipología de las causas presumidas de las guerras "basada en las funciones políticas de las guerras" 135 . Del mismo modo, cuando se refiere a sus causas económicas o demográficas, relega la política a un papel secundario. No obstante, este criterio es coherente con su total rechazo de las concepciones de la guerra que la hacen depender de la decisión política, es decir, de la voluntad humana, en el sentido de Clausewitz ${ }^{136}$.

\section{A) Lo polemológico abarca, analíticamente, lo político}

Los comentarios a la polemología de Bouthoul ilustran, desde diversos puntos de vista, la singularidad del pensamiento de Freund. La cuestión decisiva, a todos los efectos, es la de la continuidad que el autor de Sociología del conflicto 
establece entre el conflicto y lo político. Freund, según se ha señalado, concibió la polemología como el estudio del conflicto en general, fuese de naturaleza económica, religiosa, jurídica, política o de otro tipo. El presupuesto metafísico que lo justifica es que los antagonismos están en el centro de la sociabilidad humana, de modo que, en su opinión, ninguna actividad humana puede ser ajena al conflicto ${ }^{137}$. El problema, señalado por Pier Paolo Portinaro en 1992, abriendo con ello un sugestivo debate, estriba en dónde debe situarse lo político: ¿consiste lo político en una manifestación más, entre otras, del conflicto? ¿Es el conflicto, inversamente, una relación social que depende, en última instancia, de la polarización de la amistad y la enemistad política? ${ }^{138}$ Portinaro parece atribuir a Freund la reducción de lo político a lo conflictivo, lamentando que no haya desarrollado con más detalle las nociones de amistad política y la categoría sociológica del estado agonal (état agonal), caracterizado por la superación del conflicto y la inclusión de un tercero ${ }^{139}$. Tiene razón, hasta cierto punto, al atribuirle una concepción polemocéntrica del conflicto. En su opinión, la polemología freundeana debiera completarse con el estudio de las relaciones de competencia propias del estado agonal, es decir, con una agonología ${ }^{140}$.

En el fondo, las observaciones de Portinaro vuelven a llamar la atención sobre la circularidad de las relaciones entre el conflicto y la guerra, entre ésta y la política, y entre lo político y el conflicto ${ }^{141}$. La pertenencia de lo político y de la guerra a la matriz del conflicto es una cuestión estrictamente politicológica o sociológica. Es decir, pertenece al orden del estatuto científico de una disciplina. Como ha señalado Alessandro Campi, a Freund le corresponde el mérito de haber hecho del presupuesto amigo-enemigo, "no una pareja polémica de dudoso gusto ideológico o una generalización en clave filosófico-existencialista, sino un instrumento analítico perfectamente utilizable en las investigaciones empíricas"142. En este sentido, todo lo político puede ser abordado en clave polemológica, enfoque que no excluye, sin embargo, una perspectiva agonológica, por utilizar el neologismo de Portinaro, haciendo del compromiso el eje de toda la actividad política ${ }^{143}$.

Ahora bien, una cosa es la relación de subordinación de lo político a lo polemológico, establecida por Freund en Sociología del conflicto con valor epistemológico, y otra cosa es el valor fenomenológico o, si se quiere, existencial de la relación inversa, es decir, la subordinación del conflicto a lo político, apuntada por el autor en La esencia de lo político y a la cual vuelve, significativamente, en las páginas finales de Sociología del conflicto.

\section{B) Lo político abarca, existencialmente, el conflicto}

En la conclusión de Sociología del conflicto, titulada El precepto fundamental de la política, Freund señaló que «sociológicamente» léase también praxeológicamente o existencialmente, la política disfruta de un estatuto particular 
en la conflictualidad, que se corresponde, por lo demás, con su finalidad especifica"144. Lo que quiere decir Freund es que la política no es como las demás actividades humanas. Pues por su finalidad tiene un carácter envolvente de todas las manifestaciones de la vida humana colectiva ${ }^{145}$. "Todo lo que se le pide a la política es la creación de las condiciones que permitan que las otras actividades se desarrollen según su propio genio. En particular, la política debe tomar las precauciones necesarias para que los conflictos internos de las distintas actividades no degeneren en conflictos políticos, o bien, si los conflictos alcanzan finalmente esa dimensión, encontrarles una solución satisfactoria"146 . Por todo ello, en el plano de la existencia concreta, lo político deviene el gestor del conflicto.

\section{EL CONFLICTO COMO RELACIÓN SOCIAL}

La polemología de Freund, en su dimensión más fenomenológica, ofrece un elaborado concepto relacional del conflicto, inspirado directamente en la noción de lucha de la sociología formista de Simmel ${ }^{147}$. Su punto de partida es un lugar común de la experiencia humana: la evidencia de que "un conflicto sólo puede nacer con la presencia de un otro"148. En cuanto no afectan a un tercero, hay que apartar los dilemas morales de un individuo, los casos de conciencia, las contradicciones personales, etc., cuya génesis, no obstante, el freudo-marxismo cifró en la cultura y las instituciones sociales, y el Peace Research en la violencia llamada estructural. Mas las cosas no son, en este caso, tan sencillas como evidentes. El conflicto acompaña siempre a la sociabilidad humana. Si sólo se pueden tener conflictos con un tercero, ello quiere decir que lo conflictivo o lo polémico es, ante todo, una de las formas posibles en que pueden presentarse las relaciones sociales ${ }^{149}$. Para la polemología interesan menos las razones circunstanciales de un conflicto que el hecho en sí "de la elección diferente de los participantes en una relación social recíproca”, pues todo puede ser, en última instancia, objeto de conflicto en las relaciones humanas.

El conflicto no sólo tiene una faceta destructiva de las sociedades, sino también constructiva y fundadora. Por eso, la sociología dinámica ve en este elemento de la realidad una de las condiciones del cambio social ${ }^{150}$. El conflicto puede estimular respuestas positivas e imaginativas a una situación crítica que amenaza la continuidad de la comunidad.

Freund elaboró una precisa definición de conflicto para evitar en lo posible la confusión con otras nociones afines. En ella se combinan sin hiato las dimensiones fenomenológica y praxeológica de la polemología: "el conflicto, escribe, consiste en un enfrentamiento o choque intencional entre dos seres o grupos de la misma especie, que manifiestan una mutua intención hostil, por lo general con respecto a un derecho. A fin de mantener, afirmar o restablecer su derecho, cada ser o grupo intenta romper la resistencia del otro recurriendo eventualmente a la violencia, la cual, en caso de necesidad, puede tender al aniquilamiento físico del otro"151. Freund 
resaltó que todo conflicto es un choque voluntario entre miembros de la misma especie $^{152}$. Pero todavía tiene mayor relevancia la intención hostil que preside toda relación conflictiva. "La intención hostil consiste en el designio, materializado o no, de perjudicar a otro en su persona física (hiriéndole o, en última instancia, matándole), o en sus atributos materiales (posesiones) o morales (valores)"153 . Esta hostilidad pertenece al orden emocional, contrariamente a la agresividad, que es una disposición natural más o menos desarrollada y fijada en la especie. La hostilidad, por tanto, aparece y desaparece, mientras que la agresividad es, en principio, permanente. La precisión que sigue es clarificadora, sobre todo si se traslada al campo de la acción política. Comentando la posibilidad de que la intención hostil sólo sea experimentada por una de las partes, Freund señala que "es suficiente que uno de los antagonistas manifieste hostilidad para que se cree una situación conflictiva" ${ }^{54}$. Por eso, en política, basta con que el otro nos designe como enemigo para que esté amenazado el orden del grupo o, en el caso límite, su propia existencia. La intención hostil es, pues, la piedra de toque de todas las doctrinas pacifistas. La ilusión del pacifismo, a excepción, tal vez, del pacifismo maquiavelista del marxismoleninismo e ideologías similares, consiste en creer que basta con proclamar que no se tienen enemigos para que estos, reales o potenciales, desaparezcan. La bondad es incapaz de yugular los conflictos. Este irenismo resulta, de hecho, polemógeno ${ }^{155}$.

\section{EL CONFLICTO COMO ACTIVIDAD ESPECÍFICA}

La definición freundeana del conflicto comprende otros dos elementos, esenciales desde el punto de vista praxeológico. Por un lado la idea de derecho, que preside teleológicamente toda la dinámica conflictiva ${ }^{156}$. En opinión de Freund, "el objeto del conflicto es, en general, mas no siempre, el derecho, a condición de que no se entienda por derecho únicamente una disposición formal, sino también una reivindicación de justicia"157. En esto se basa la teoría polemológica del derecho de Freund ${ }^{158}$. Su tesis es que en el corazón de todo conflicto alienta un sentimiento del derecho y de la justicia, lo cual explica la distinción entre reglas (règles) y normas (normes). "El conflicto, decía, estalla cuando se opone una norma a una regla, siendo la revolución una típica ilustración de este hecho"159. La regla es una convención positivizada que establece una dicotomía, garantizada coactivamente, entre lo que está prohibido y lo que está permitido. La norma es un valor o un ideal al que se aspira, sin imponer necesariamente una coacción.

El conflicto es no sólo una relación social, ya que, como tal conflicto, da también lugar a una actividad específica ${ }^{160}$. "Un conflicto, dice el autor, no es el producto objetivo de una situación, aunque las circunstancias puedan tener un peso considerable, sino la consecuencia de la voluntad subjetiva de personas, grupos o colectividades que buscan quebrantar la resistencia que otro opone a sus intenciones o a su proyecto"161 . La idea del acto conflictivo, imprescindible para una praxeología 
de la conflictividad, abarca la reflexión sobre el derecho, considerado su finalidad formal ${ }^{162}$; mas también el análisis de los medios inherentes al conflicto, que van, desde la violencia hasta la negociación, recorriendo una amplia escala. Pues, "el conflicto, como toda acción humana, está sujeto empíricamente a la relación del fin y los medios" $" 163$. En la práctica, los medios pueden ser tan variados como los fines concretos o particulares perseguidos. Se prefieran unos u otros, "el imperativo mayor de todo conflicto es la economía de medios", no sea que la desproporción o el exceso termine anulando los beneficios que se espera obtener ${ }^{164}$.

De una lectura integradora de la obra polemológica de Freund se deduce, sin forzar su pensamiento, el carácter central que ocupan la violencia y la negociación en la reflexión sobre los medios del conflicto ${ }^{165}$. Es casi un lugar común afirmar que un conflicto se soluciona recurriendo o a la violencia o a la negociación ${ }^{166}$. La violencia, inexorablemente, está siempre al acecho en toda relación social ${ }^{167}$; la negociación en múltiples formas, aparece siempre, antes o después, en la dinámica conflictiva, exceptuando, tal vez, los casos límite del terror revolucionario y del genocidio ${ }^{168}$.

"La violencia es el medio último y radical que remata el conflicto y le da toda su significación"169. Lo significativo del recurso a la violencia es que descarta la utilización de otros medios para someter la voluntad del adversario. Mas no toda violencia es abierta o directa, entendiendo por tal "la que se ejerce en el transcurso de una agresión caracterizada por amenazas, golpes y tal vez con armas". Existe una violencia de situación o indirecta mucho más insidiosa, socialmente difuminada y promovida por regímenes totalitarios que recurren al internamiento en campos de trabajo y hospitales psiquiátricos. "Este tipo de violencia puede adoptar en ocasiones formas agudas y espectaculares, como las del terror (en primer lugar el terrorismo gubernamental), pero con más frecuencia, continúa Freund, presenta la apariencia hipócrita de un régimen de miedo generalizado y de intimidación permanente" 170 . Así pues, es posible distinguir entre una especie de violencia propia de una dinámica conflictiva y otra especie de violencia que se genera sin conflicto, o al menos sin un conflicto abierto o declarado ${ }^{171}$.

En el otro extremo de la escala de medios está la negociación, a la que normalmente rodea un halo de moralidad. Según la opinión vulgar que se tiene de la negociación, ésta sería el único medio justo, incluso el único medio democrático o verdaderamente pacifista, para alcanzar soluciones aceptables para las dos partes. ¡Como si la violencia, aunque sea impopular, no fuese la ultima ratio en situaciones sin salida o que no admiten otro tipo de contemplaciones! Freund advertía siempre contra las mistificaciones de la literatura apologética de la negociación, pues no le parecía que ese método fuese universalmente válido ${ }^{172}$. Es posible que un compromiso perjudicial sea menos oneroso que la derrota en una guerra penosa. ¿Por qué negar, según el mismo razonamiento, la posibilidad de que, en ciertas condiciones históricas, sea preferible la guerra al entreguismo de un mal acuerdo, capaz sólamente de retrasar o agravar la disputa de fondo? Valórese, en este sentido, 
la parte de irresponsabilidad política que hubo en los acuerdos de Munich de 1938, cuyo único efecto real fue retrasar la guerra y dar más tiempo a Hitler. No hay que descartar, pues, que la obstinación por conseguir salidas negociadas ahogue las posibilidades reales de solucionar un contencioso ${ }^{173}$. Freund hubiese suscrito gustoso la siguiente regla práctica enunciada en tantas ocasiones por el filósofo español Julián Marías: no hay que intentar contentar a quien nunca se va a contentar.

Dejando a un lado sus acepciones vulgares e impropias ${ }^{174}$, la negociación es para Freund un procedimiento de intercambios entre personas o representantes de grupos para dirimir una diferencia de opiniones o intereses ${ }^{175}$. La negociación tiene dos limitaciones muy concretas. Por un lado, al aceptar esta vía para la solución de conflictos, cada adversario se obliga a reconocerle al contrario ciertos derechos o cualidades. Dicho con un lenguaje propio del jus gentium europaeum: la contraparte es siempre un adversario justo. O se renuncia a imponer desde el principio una decisión unilateral o la negociación estará abocada al fracaso ${ }^{176}$. No menos importante, según el autor, es tener presente en cada caso que no todo es negociable, pues "existen principios y valores, lo mismo para la naciones que para los grupos, sobre los que no se puede transigir sin perder la razón de ser, la independencia, la identidad o, simplemente, la libertad de maniobra" 177 .

\section{CONCLUSIONES}

La obra de Julien Freund está llamada a ocupar un lugar relevante en el panorama intelectual de los próximos años, cuando la libertad y la independencia del espíritu científico se impongan sobre el political correctness. Entonces, la inteligencia política, sociológica y, por qué no, económica deberán reconocer el valor intelectual y personal del gran universitario francés, quien siempre rechazó de plano el llamado pensamiento único. De natural vehemente, reactionnaire de gauche se titulaba a veces con afán polémico, nunca se opuso a la libre confrontación de opiniones. En el plano de las ideas buscó siempre cordialmente al enemigo, pues creía, siguiendo en esto a Carl Schmitt, que el enemigo es siempre parte de nosotros mismos. Si tienes un enemigo, podría haber escrito, eres afortunado; ¿para qué necesitas convencerle?

En el contexto de la filosofía y la ciencia políticas correspóndele a Freund el mérito de haber despejado la confusión entre Político (le politique) y política (la politique), diferenciación ya apuntada, por cierto, en la distinción schmittiana Político (das Politischen) y Estado (Staat). Su sociología del conflicto o Polémologie se enmarca, justamente, en el desarrollo de la noción de esencia (essence) de lo Político, hasta el punto de establecer a partir de ella el tipo de relaciones que median entre la acción política y el conflicto.

Mas la Polemología freundeana no se agota, ni mucho menos, en la oportunidad de un libro manual universitario, pues su idea del conflicto, elaborada 
epistemológicamente como un "concepto unívoco", le permitió elaborar sugestivas categorías científicas muy útiles, por ejemplo, para la interpretación de las guerras y de lo bélico en general (lucha y combate), para el estudio politicológico de los sistemas políticos (estado agonal y estado polémico) e, incluso, para la exposición sistemática de lo que llamó teoría polemológica del Derecho. Sería de esperar, por tanto, que en los próximos años se produjese la recepción e incorporación definitivas de la Polemología freundeana al acervo de la sociología europea, tal vez demasiado centrada en lo irenológico, cuando no en el puro irenismo. 


\section{NOTAS}

${ }^{1}$ La cité de l'homme, Fayard, Paris, 1994, p. 113.

${ }^{2}$ De todos ello ha dado cuenta de una manera exhaustiva P. TOMMISSEN, "La bibliografia di Julien Freund", en Studi Perugini, 1, 1996.

${ }^{3}$ Los estudios freundeanos en España e Hispanoamérica son relativamente recientes, aunque existen traducciones españolas de sus escritos de los años 1960. Especial interés tiene la traducción de L'essence du politique (Sirey, 1965), su tesis doctoral y opus magna (Editora Nacional, 1968). El año 1994, después de años de ausencia de las páginas españolas, apareció su artículo "Algunas ideas sobre lo político" (Hespérides, Núm. 4/5. 1994). A este le siguió la traducción del libro que sistematiza sus concepciones polemológicas, Sociología del conflicto (Ediciones Ejército, 1995). En 1997 la Fundación Cánovas del Castillo editó nuestro trabajo La filosofía económica de Julien Freund ante la economía moderna, exposición de la noción freundeana de lo Económico en la que hemos vuelto a abundar en 1998: "La esencia de lo Económico. Acerca de las relaciones entre la economía, la política y la política social en el pensamiento de Julien Freund”, en Hespérides, núm. 18. Entre tanto han aparecido sendas traducciones argentinas de Qu'est-ce que la politique? y Le droit d'aujourd'hui (Universidad Nacional del Sur, 1996. Trad. de N. L. Montezanti). Con posterioridad ha aparecido nuestro artículo «Democracia moral y teoría de las formas de gobierno en Julien Freund», Hespérides, nº 20, 1999.

${ }^{4}$ Véase MOLINA, J., Julien Freund, lo político y la política,(Sequitur, 2000). Cabe esperar, acaso en un corto plazo, la floración de los estudios freundeanos.

${ }^{5}$ No obstante, la sociología del conflicto de Julien Freund se proyecta más allá de lo estrictamente sociológico, pues de sus presupuestos se nutre la original filosofía del derecho del escritor, lo que él denominó la teoría polemológica del derecho. Sobre este extremo: MOLINA, J., De la Polemología a la Filosofía de lo Jurídico, prólogo de A. Campi, (en prensa).

6 "Ébauche d'une autobiographie intellectuelle", Revue Européenne des sciences sociales, vol. $19, \mathrm{n}^{\circ} .54-55,1982$, p. 45.

${ }^{7}$ FREUND, J., "Raymond Aron, directeur de thèse", Commentaire, vol. 28, $\mathrm{n}^{\circ} 28$ 29,1985 . Al no haber podido consultar esta revista, citamos por el original mecanoscrito de la biblioteca del autor: documento EC17, hojas 2-3.

${ }^{8}$ Véase FREUND, J., "Topique de la polémologie", Res Publica, vol. XIX, nº 1, 1971. Este artículo es considerado por Piet Tommissen como el manifiesto fundacional de la disciplina y de la institución.

${ }^{9}$ Véase FREUND, J., "L'institut de Polémologie de Strasbourg", Revue de Sciences Sociales de la France de l'Est, no 4, 1975, p. 333.

${ }^{10}$ FREUND, J.,"Ébauche d'une autobiographie intellectuelle”, op. cit. p. 31.

${ }^{11}$ En 1972 fundó también la Revue de Sciences Sociales de la France de l'Est. 
Dos años antes, en 1970, Freund aceptó el encargo de dirigir para Marcel Rivière la nueva serie de la colección Études sur le devenir social, fundada originalmente por Georges Sorel.

${ }^{12}$ Julien Freund, socialista en su juventud por convicción, combatió la Ocupación alemana en el grupo de obediencia comunista F. T. P. F. (Franc-Tireurs et Partisans Français). Acabada la guerra, sus ideales se vieron superados por la lucha maquiavelista para desplazar al rival de los puestos políticos y administrativos. Su choque con los comunistas fue frontal, hasta el punto de sufrir un atentado en la plaza del mercado de Sarrebourg, del que salió ileso de milagro. La piedra guarda todavía memoria del impacto de la bala. A resultas de estos y otros avatares, Freund abandonó toda responsabilidad en la dirección de un periódico regional, L'Avenir Lorrain, para preparar su agregaduría en filosofía y concentrarse en su tesis doctoral sobre la esencia de lo Político, la única forma, según sus propias palabras, de sobreponerse a la decepción de lo político.

13 "Ébauche d'une autobiographie intellectuelle", op. cit. p. 47.

${ }^{14}$ ARON, R., Las etapas del pensamiento sociológico, Siglo XX, Buenos Aires, vol. II, p. 11.

${ }^{15}$ Miguel de Unamuno, enemigo declarado del sociologismo, aunque él mismo tuvo aguda mirada de sociólogo, expuso estas mismas cuestiones en un libro que Freund apreció y que gustaba citar: "una enorme actividad social, una poderosa civilización, mucha ciencia, mucho arte, mucha industria, mucha moral, y luego, cuando hayamos llenado el mundo de maravillas industriales, de grandes fábricas, de caminos, de museos, de bibliotecas, caeremos agotados al pie de todo esto, y quedará ¿para quién?". Del sentimiento trágico de la vida, Espasa-Calpe, Madrid, 1993, p. 56.

16 "La política como vocación". El político y el científico, Alianza, Madrid, 1992, p. 177.

17 "El grandioso racionalismo de una vida ética y metódicamente ordenada que resuena en el fondo de toda profecía religiosa destronó aquel politeísmo en favor de 'el único que hace falta', pero después, enfrentado a las realidades de la vida interna y externa, se vio obligado a esos compromisos y relativizaciones que conocemos por la historia del Cristianismo. Hoy todo eso es ya rutina". WEBER, M., "La ciencia como vocación". El político y el científico, p. 217. Véase FREUND, J., "Polythéisme des valeurs et monothéisme réligieux", Études sur Max Weber, Ginebra.,Droz, 1990, pp. 65-201. También, FREUND, J., "Die industrielle Konfliktgesellschaft", Der Staat, vol. 16, n 2, 1977.

18 "La política como vocación", El político y el científico, p. 173.

${ }^{19}$ Véase "Rationalisation et desenchantement". Études sur Max Weber, p. 89.

${ }^{20}$ Por ejemplo, en el libro Max Weber, P.U.F., París, 1969.

${ }^{21}$ Études sur Max Weber, p. 3.

${ }^{22}$ Sobre el pensamiento de Javier Conde, que constituye en sí mismo un capítulo de la ciencia y la sociología políticas españolas: MOLINA, J., "Realismo politico spagnolo: Francisco Javier Conde", Studi Perugini, no 8, 1999; "Javier Conde y el 
realismo político", Razón Española, n 100. 2000.

${ }^{23}$ Véase "Espejo del caudillaje". Escritos y fragmentos políticos, Instituto de Estudios Políticos, Madrid, 1974, pp. 365-394.

${ }^{24}$ Mémoires. 50 ans de réflexion politique, Julliard, Paris, 1983, p 145.

${ }^{25}$ Véase WEBER, M.,,Essais sur la théorie de la science. Reeditado en 1992 por las Presses Pocket.

${ }^{26}$ P.U.F., Paris, 1966.

${ }^{27}$ Études sur Max Weber, p. 3.

${ }^{28}$ Max Weber, $p .14$.

${ }^{29}$ Véase FREUND, J., (1974): Pareto. La théorie de l'équilibre, Seghers, París, p. 13.

${ }^{30}$ La síntesis precisa y sugerente de todos ellos en FREUND, J., Pareto. La théorie de l'équilibre.

${ }^{31}$ Véase "Julien Freund, une esquisse bio-bibliographique", en FREUND, J., (1984):

Philosophie et sociologie, La Nueva. Cabay, Lovaina, p 420.

32 PARETO, V., (1987): Escritos sociológicos, Alianza, Madrid, 1987, p 91. Asimismo FREUND, J., L'essence du politique, cap. X.

${ }^{33}$ Véase ARON, R., (1995): "Lectures de Pareto". Machiavel et les tyrannies modernes, Fallois, Paris, 1995, p. 278.

${ }^{34}$ Esta idea es desarrollada también por Freund en "Autorité politique et conduite économique". Économies et sociétés, Cahiers de l'I.S.E.A, vol. 7. ,nº 1-2, 1974.

${ }^{35}$ FREUND, J., Pareto. La théorie de l'équilibre, pp.. 190-194.

${ }^{36}$ PARETO, V., La théorie de l'équilibre, pp. 183 y ss.

${ }^{37}$ PARETO, V., (1980): Forma y equilibrio sociales. Extracto del tratado de sociología general, Alianza Editorial, Madrid, § 2174, p. 117. Véase también FREUND, J., "Le pouvoir est-il révolutionnaire ou réactionnaire?". Politique et impolitique, Sirey, Paris, 1987.

${ }^{38}$ PARETO, V., Escritos sociológicos, p. 91.

${ }^{39}$ PARETO, V., Forma y equilibrio sociales. Extracto del tratado de sociología general, $\S 2251$, p. 161.

${ }^{40}$ La teoría freundeana de la decadencia entendida como una categoría de la de la interpretación histórica, es deudora de las ideas de Pareto. Véanse FREUND, ., (1984): La décadence. Histoire sociologique et philosophique d'une catégorie de l'expérience humaine, Sirey, Paris, p.. 170. L'aventure du politique. París. Criterion. 1991, pp. 119-150, "De la décadence". Contrepoint, n 18, 1975.

${ }^{41}$ FREUND, J., introducción a. SIMMEL, G., Sociologie et épistémologie, P.U.F., Paris, 1981, p. 9.

${ }^{42}$ Introducción a SIMMEL, G., Sociologie et épistémologie, p. 11.

${ }^{43}$ Véase El hombre y la gente, Espasa-Calpe, Madrid,1986.

${ }^{44}$ Sociología, Estudios sobre las formas de socialización, Alianza, Madrid, 1986, 2 vols.

${ }^{45}$ Véase La rebelión de las masas, Espasa-Calpe, Madrid, 1992, cap. I. 
${ }^{46}$ Sociologie et épistémologie, p. 164.

${ }^{47}$ Sociologie et épistémologie, pp. 107-119.

${ }^{48}$ Simmel habló de una formal Soziologie y no de una formell Soziologie. Mientras que formal hace referencia a la forma, formell califica aquello que es formal, es decir, lo que respeta las formas. "Lo que Simmel quiere decir cuando aplica el término alemán formal a la sociología, escribe Freund, es que se trata de una ciencia relativa a las formas y no una ciencia formal". La traducción del concepto a lenguas como la española o la francesa, que no tienen ese matiz, puede producir equívocos. La traducción propuesta por Freund es sociologie formale (por oposición a sociologie formelle). Michel Maffesoli, en cambio, se inclina por sociologie formiste. En español, la única posibilidad de evitar la confusión es traducir formal Soziologie por sociología formista. Introducción a. SIMMEL, G., Sociologie et épistémologie, p. 49.

${ }^{49}$ SIMMEL, G., Sociologie et épistémologie, p. 90

${ }^{50}$ Sociología, vol. I, p. 17.

${ }^{51}$ Sociología, vol. I, p. 21.

${ }^{52}$ Sociología, vol. I, p. 265.

${ }^{53}$ Sociología, vol. I, p. 278.

${ }^{54}$ P. 19.

${ }^{55}$ Véase LE BON, G., (1972): Psicología de las multitudes, Albatros, Buenos Aires. Albatros, p. 17.

${ }^{56}$ Véase LE BON, G.,(1921): Psicología del socialismo, Daniel Jorro, Madrid, p. 85-102.

57 "Notes sur Gabriel Tarde et Gustave Le Bon". D'Auguste Comte à Max Weber, Paría, Economica, 1992. p. 152.

${ }^{58}$ Véase SIMMEL, G., Sociologie et épistémologie, p. 93.

${ }^{59}$ Véase FREUND, J., Pareto. La théorie de l'équilibre, cap. V. También Max Weber, pp. 13-68.

${ }^{60}$ Philosophie et sociologie, p. 7.

${ }^{61}$ Philosophie et sociologie, p. 19.

${ }^{62}$ Por nuestra parte, apoyándonos en la teoría epistemo-fenomenológica de las esencias, hemos inquirido en la temática de la política social. Véase MOLINA, J., Introducción en la teoría de la Política Social. Murcia, DM, 2000.

${ }^{63}$ El término es de ZUBIRI, X., (1987): "El acontecer humano". Naturaleza, historia y Dios, Alianza, Madrid, p. 376.

${ }^{64}$ ARISTÓTELES, (1970): Política, Instituto de Estudios Políticos, Madrid. I,2. ${ }^{65}$ FREUND, J. (1990): Philosophie philosophique, La Découverte, Paris, p.110. ${ }^{66}$ FREUND, J., L'essence du politique, p. 83.

${ }^{67}$ Philosophie et sociologie, p. 28.

${ }^{68}$ Philosophie philosophique, p. 108.

${ }^{69}$ Véase Investigaciones en antropología política, Gedisa, México, 1987, cp.6 y 7,cfr. DE LA BOËTIE, E., (1995): Discurso de la servidumbre voluntaria o el contra uno, Tecnos, Madrid. 
${ }^{70}$ FREUND, J., Philosophie et sociologie, p. 27. L'essence du politique, p. 141. Sociologie du conflit, P.U.F., Paris, 1983, p. 150.

${ }^{71}$ Philosophie et sociologie, p 34.

${ }^{72}$ Philosophie et sociologie, p. 27.

${ }^{73}$ La teoría de las esencias de Freund merece por sí misma un estudio monográfico. Ha reparado en ella ALESSANDRO CAMPI, quien la expone sintéticamente en su introducción a FREUND, J., (1995): Il terzo, il nemico, il conflitto. Materiali per una teoria del Politico, Giuffrè, Milán, pp. 9-13. También en MOLINA, J., "La esencia de lo económico. Acerca de las relaciones entre la economía, la política y la política social en el pensamiento de Julien Freund",.op. cit.

${ }^{74}$ L'essence du politique, p. 25.

${ }^{75}$ FREUND, J. (1993): L'essence de l'économique, Presses Universitaires de Strasbourg, Estrasburgo, p. 35.

${ }^{76}$ Philosophie et sociologie, pp. 41-81.

${ }^{77}$ L'essence du politique, p. 84.

${ }^{78}$ L'essence du politique, p. 87.

${ }^{79}$ L'essence de l'économique, p. 54.

${ }^{80}$ L'essence du politique, p. 699.

${ }^{81}$ L'essence du politique, p. 668.

${ }^{82}$ Philosophie et sociologie, pp. 41-81.

${ }^{83}$ Philosophie et sociologie, p. 79. También, "Observation sur la finalité respective de la technique et de l'éthique". Annales del'Institut de Philosophie et de Sciences morales, 1983.

${ }^{84}$ P. 73, cfr. SPRANGER, E., Formas de vida: psicología yética de la personalidad.

${ }^{85}$ Philosophie philosophique, p. 110.

${ }^{86}$ L'essence du politique, p. 98.

${ }^{87}$ Véase FREUND, J., "La cuestión social", Cuadernos de Trabajo Social, nº 18, 1998.

${ }^{88}$ Véase Le droit d'aujourd'hui, P.U.F., Paris, 1972.

${ }^{89}$ Véase De Comte à Max Weber, p.11. También FREUND, J., "Die industrielle Konfliktgesellschaft". Der Staat, vol.16, n² 2, 1977. En este artículo (p. 161) escribe Freund que la "sociología es una ciencia y no una ideología crítica de la sociedad, es decir, un análisis de la sociedad como tal sociedad (eine Analyse der existirenden Gesellschaft)".

${ }^{90}$ Véase Essais sur la violence banale et fondatrice, Librairie des Méridiens, Paris, 1984, p 9

${ }^{91}$ Sobre las mentiras contemporáneas poco habría que añadir a lo expuesto por REVEL, J.F., (1989): El conocimiento inútil, Planeta, Barcelona.

${ }^{92}$ Sobre lo que significa ser reaccionario véase MARQUÉS DE TAMARÓN, "La reacción y los reaccionarios". El siglo XX y otras calamidades, Pre-Textos Valencia, 1997.

${ }^{93}$ Philosophie et sociologie, pp. 8-17. Sobre la disyuntiva epistemológica que opone a la consideración de la Sociología como una verdadera ciencia, la consideración de 
la misma como un conjunto de investigaciones, Philosophie et sociologie, p. 7. ${ }^{94}$ Philosophie et sociologie, p. 8. Véase también ARON, R., (1970):Dix-huit leçons sur la société industrielle, Gallimard, Paris, p. 23

${ }^{95}$ Véase BOUDON, R., (1994): La logique du social, Hachette, Paris, p. 9.

${ }^{96} \mathrm{El}$ abstraccionismo piensa la realidad únicamente según las ideas 3/4que sólo son una parte de la realidad, normalmente la más superficial $13 / 4$. Véase ORTEGA Y GASSET, J. Ideas y creencias. También MOLINA, J., (1997): "La supuesta apoliticidad del liberalismo". El pensamiento liberal en el fin de siglo, Fundación Cánovas del Castillo, Madrid, pp. 99-100.

${ }^{97}$ Sociologie du conflit, p. 41.

${ }^{98}$ Véase HAYEK, F.A., (1979): The Counter-Revolution of Science, Liberty Press, Indianápolis, p. MANENT, La cité de l'homme.

${ }^{99}$ Sociologie du conflit, p. 56.

${ }^{100}$ FREUND, J., D'Auguste Comte à Max Weber, p. 11.

${ }^{101}$ D'Auguste Comte à Max Weber, p. 107.

${ }^{102}$ Obsérvese que Bouthoul utiliza el plural mientras que Freund usa el singular. La gran obra de Bouthoul es Traité de polémologie. Sociologie des guerres, Payot, Paris, 1991.

${ }^{103}$ Véase GINER, S. (1974): El progreso de la conciencia sociológica, Península, Barcelona, p. 180.

${ }^{104}$ Sociologie du conflit,.p. 249.

${ }^{105}$ ¿Fortuna histórica o "secular atraso"? Dejemos la polémica a los especialistas en tragedias nacionales.

${ }^{106}$ Véase BOUTHOUL, G., op. cit. p. 534.

${ }^{107}$ Sociologie du conflit, p. 101.

${ }^{108}$ Sociologie du conflit, p. 57.

109 "Violencia, paz e investigación sobre la paz", Investigaciones teóricas, Tecnos, Madrid, 1995, p. 314.

${ }^{110}$ Sociologie du conflit, p. 57, cfr. DEL ARENAL, C., (1987): Introducción a las relaciones internacionales, Tecnos, Madrid, pp. 327-328.

111 "Violencia, paz e investigaciónes sobre la paz", op. cit. p. 322.

112 Sociologie du conflit, p. 103. También Utopie et violence, Paris, Marcel Rivière, 1978. p. 130.

113 "Violencia, paz e investigación sobre la paz", op. cit. p. 315.

${ }_{114}$ Sociologie du conflit, p. 104.

115 "Violencia, paz e investigación sobre la paz", op. cit. pp. 313 y 347.

${ }^{116}$ Sociologie du conflit, p. 106.

${ }^{117}$ Sociologie du conflit, p. 56.

${ }^{118}$ Véase BOUTHOUL, G., (1972): Lettre ouverte aux pacifistes, Albin Michel, París, p. 10.

${ }^{119}$ Véase FREUND, J., Sociologie du conflit, p. 347.

120 Sociologie du conflit, p. 60, véase también FREUND, J., "Le fond de la pensée 
de Gaston Bouthoul". Études polémologiques, $\mathrm{n}^{\circ} 24,1981$.

${ }^{121}$ BOUTHOUL, G., Traité de polémologie, p. 3.

${ }^{122}$ BOUTHOUL, G., op. cit. pp. 14 y ss.

${ }^{123}$ BOUTHOUL, G., op. cit. p. 535.

${ }^{124}$ BOUTHOUL, G., op. cit. p. 539.

${ }^{125}$ BOUTHOUL, G., op. cit. p. 4.

${ }^{126}$ Estas estructuras son tratadas en las partes $4^{\mathrm{a}}$ a $7^{\mathrm{a}}$ de su tratado.

${ }^{127}$ BOUTHOUL, G., op. cit.. $8^{\text {a }}$ parte. También FREUND, J., Sociologie du conflit, p. 126.

${ }^{128}$ BOUTHOUL, G., op. cit. pp. 35-37.

${ }^{129}$ Sociologie du conflit, p. 60.

${ }^{130}$ Sociologie du conflit, pp. 60-61. También "Topique de la polémologie", Res Publica, vol. XIX, nº $1,1971$.

${ }^{131}$ Véase TOMMISSEN, P., "Contributions de Carl Schmitt à la polémologie", Revue européenne de sciences sociales, $\mathrm{n}^{\circ}$ 44, 1978. También CAMPI, A., "Trittico sulla guerra: Schmitt, Aron, Freund”. I Quaderni di Avallon, nº 35, 1995.

${ }_{132}$ Sociologie du conflit, p. 13.

${ }^{133}$ Véase la introducción de CAMPI, A., a FREUND, J.; Il terzo, il nemico, il conflitto. Materiali per una teoria del Politico, p. 24.

${ }^{134}$ Compárese FREUND, J., L'essence du politique, (pp.540-545) y Sociologie du conflit (pp. 70-78).

135 Traité de polémologie, p. 459.

${ }^{136}$ No quiere decirse con esto que Bouthoul fue anticlausewitziano. En una línea próxima a la de Bouthoul, FRAGA IRIBARNE, M., ha señalado que "casi siempre la guerra es cosa de necesidad más que de voluntad". Guerra y conflicto social, Instituto de Estudios Políticos, Madrid, 1962, p. 60.

${ }^{137}$ Sociologie du conflit, p. 361.

${ }^{138}$ Véase PORTINARO, P.P. "Sociologia del conflitto e teoria del politico". En MORANI, M., PORTINARO, P.P. y VITALE, A. (1992): Amicus (inimicus) hostis. Le radici concettuali della conflittualità 'privata' e della conflittualità 'politica, Giuffrè, Milán, p. 299.

${ }^{139}$ Véase FREUND, J., Sociologie du conflit. pp. 79 y ss.. PORTINARO, P.P., "Sociologia del conflitto e teoria del politico", op. cit. pp. 298-300.

140 "Sociologia del conflitto e teoria del politico", op.cit. p. 300.

${ }^{141}$ Véase MOLINA, J., Julien Freund, lo político y la política. pp. 221 y ss.

142 "Trittico sulla guerra: Schmitt, Aron, Freund". I Quaderni di Avallon, $\mathrm{n}^{\circ} 35$, 1995, p. 112.

${ }^{143}$ Véase SIMMEL,G., Sociología. Estudios sobre las formas de socialización, cap. IV. JOUVENEL, B. de, (1965): Teoría pura de la política, Revista de Occidente, Madrid.

${ }^{144}$ Sociologie du conflit, p. 361. 
${ }^{145}$ L'essence du politique, p. 277.

${ }^{146}$ Sociologie du conflit, p. 362.

${ }^{147}$ Op. cit. p. 113.

${ }^{148}$ Op. cit. p. 19.

${ }^{149}$ Op. cit. pp. 20 y ss. SIMMEL, G., Sociología, vol. 1, cap. IV.

${ }^{150}$ Sociologie du conflit, p. 117. Véanse también MAFFESOLI, M., Essais sur la violence banale e fondatrice. BOUTHOUL, G., Traité de polémologie, pp. 5-7.

${ }^{151}$ Sociologie du conflit, p. 65.

${ }^{152}$ Sobre la violencia intraespecífica, concepto de LORENZ, K., justamente apreciado por Freund, véase la famosa obra de este pionero de la etología Sobre la agresión, El pretendido mal, Siglo XX, Madrid, 1982.

${ }_{153}$ Sociologie du conflit, p. 177.

${ }_{154}^{154}$ Op. cit. p. 67.

${ }^{155}$ Véase FREUND, J., "Les obstacles à la paix". Le nouvel âge. Paris. Marcel Rivière. 1970. pp. 194 y ss.

${ }^{156}$ Freund toma esta noción de BEAUCHARD, J., (La dynamique conflictuelle) para referirse a la génesis de los conflictos, a sus causas y motivaciones, al ámbito de sus reivindicaciones y antagonismos y, por último, al denominado umbral del conflicto (seuil conflictuelle) o momento que determina la transformación de una relación social cualquiera en un conflicto. El desarrollo en Sociologie du conflit, especialmente en el tercer capítulo. La investigación sobre el umbral de los conflictos trata, pues, de dar respuesta a una espinosa pregunta: "¿según que proceso las reivindicaciones, las tensiones y los antagonismos desembocan en el conflicto?" (Sociologie du conflit. p. 167). Un momento decisivo de toda relación social es aquel en el que la exclusión del tercero (tiers exclu) da paso a la polaridad amigo/ enemigo (op. cit. pp. 287-288).

${ }^{157}$ Sociologie du conflit, p. 67.

${ }^{158}$ Véase especialmente FREUND, J., "Droit et conflit". Politique et impolitique. pp. 303-318.

${ }^{159}$ Sociologie du conflit, p. 90.

${ }^{160}$ Véase la distinción de Freund entre conflicto, juego, crisis y dialéctica, op. cit. pp. 303-327.

${ }^{161}$ Op. cit. p. 304.

162 Op. cit. p. 222 en relación con pp. 65 y ss., y 90.

${ }^{163}$ Op. cit. p. 221.

${ }^{164}$ Op. cit. p. 223.

${ }^{165}$ Cfr. P. PORTINARO, P.P.., "Sociologia del conflitto e teoria del politico", op. cit. pp. 299 y ss.

${ }_{166}$ Sociologie du conflit, p. 279.

${ }^{167}$ Op. cit. p. 69.

${ }^{168}$ Op. cit. p. 279. 
169 Op. cit. p. 97.

${ }^{170}$ Op. cit. p. 100.

${ }^{171}$ Op. cit. p. 100. También Utopie et violence. pp. 165 y ss.

${ }_{172}$ Sociologie du conflit, p. 282.

${ }^{173}$ Op. cit. pp. 282-283.

${ }^{174}$ Para la jerga postmoderna del igualitarismo, la negociación es algo que, al parecer, debe presidir todas las relaciones humanas: desde la relación maestro-discípulo hasta la relación de los amantes, pasando por la vasta escala de las relaciones laborales, paterno-filiales, conyugales y amistosas.

${ }^{175}$ Sociologie du conflit, p. 279.

${ }^{176}$ Op. cit. p. 280.

${ }^{177}$ Op. cit. p. 284. 